\title{
El DILEMA DEL PRISONERO: REFLEXIONES CRÍTICAS SOBRE LA JURISPRUDENCIA DEL TRIBUNAL EUROPEO DE DERECHOS HUMANOS EN MATERIA DE DERECHO DE VOTO DE LOS CONDENADOS
}

\section{The dilemma prisoner - critical reflections on the case law of the european court of human rights on voting rights of the damned}

\section{Marco Olivetti}

Professore ordinario di diritto costituzionale nel Dipartimento di Giurisprudenza dell'Università di Foggia (Italia). E' autore di circa 200 saggi su riviste giuridiche italiane e internazionali e delle monografie "La questione di fiducia nel sistema parlamentare italiano" (Giuffrè, Milano, 1996), "Nuovi statuti e forma di governo delle Regioni" (Il Mulino, Bologna, 2002) e "Messico" (Il Mulino, Bologna, 2013, collana "Si governano cosi”"). Ha coordinato, con Raffaele Bifulco e Alfonso Celotto, il "Commentario alla Costituzione" (Utet, Torino, 2006, 3 volumi). E' stato componente della Commissione per le riforme costituzionali nominata nel 2013 dal governo italiano.E-mail: m.olivetti65@gmail.com.

Sumário: 1. La restricción del derecho de voto en consecuencia de una condena penal: del derecho penal al derecho constitucional. 2. Los derechos políticos en el Convenio Europeo de Derechos Humanos: las libertades de reunión y de asociación. 3. La garantía de elecciones libres y secretas. 4. Las limitaciones del derecho de voto compatibles con el Convenio y el problema de los condenados a una pena de prisión. 5. La jurisprudencia del TEDH sobre el derecho de voto de los prisoneros: el caso Hirst contra Reino Unido. 6. El caso Frodl v. Austria. 7. El caso Greens y el caso Scoppola 3. 8. Las decisiones de 2013: los casos Firth, Anchugov and Gladkov y Söyler. 9. Notaciones críticas. 9.1. Críticas de método. 9.2. Para una justificación teórica plausible de la privación del derecho de voto de los condenados.

\section{LA RESTRICCIÓN DEL DERECHO DE VOTO EN CONSECUENCIA DE UNA CONDENA PENAL: DEL DERECHO PENAL AL DERECHO CONSTITUCIONAL}

En las últimas dos décadas el tema de la privación del derecho de voto de los autores de crímenes condenados a una pena que comporta la privación de la libertad personal se ha convertido en unos de los objetos privilegiados del diálogo entre las jurisdicciones de diferentes sistemas jurídicos ${ }^{203}$, que es una de las dimensiones más

${ }^{203}$ Como es bien sabido, dicho diálogo tiene una dimensión «horizontal», en la cual estan 
interesantes del constitucionalismo contemporaneo. Varias sentencias de Tribunales supremos o constitucionales fueron adoptadas en Sudáfrica ${ }^{204}$, Canadá ${ }^{205}$, Austrlia ${ }^{206}$, Israel $^{207}$, Estados Unidos ${ }^{208}$, México $^{209}$. A estas sentencias se añadió después de 2004

envolucrados jueces de diferentes ordenes jurídicos estatuales, y una dimensión «vertical», que concierne las relaciones entre jueces internacionales o supranacionales. Para una síntesis de unos problemas planteados por dicho diálogo se v. G. De Vergottini, Oltre il dialogo tra le Corti. Giudici, diritto straniero, comparazione, Il Mulino, Bolonia, 2010.

204 August v. Electoral Commission, 1999 (3) SALR 1, 15 n. 30 (CC) (S. Afr.), que fue adoptada en ausencia de una «disqualifying rule» prevista por la ley y Minister of Home Affairs $v$ National Institute for Crime Prevention and the Reintegration of Offenders (NICRO) 2005 (3) SA 280 (CC).

${ }^{205}$ Sauvé v. Canada (Attorney General), [1993] 2 S.C.R. 438, (1992), 7 O.R. (3d) 481 (según la cual un «blanket disenfranchisement» es inconstitucional porqué el derecho de voto es garantizado por la Carta canadiense de derechos y libertades sin la previsión de limitaciones) y Sauvé v. Canada (Chief Electoral Officer), [2002] 3 S.C.R. 519, 2002 SCC 68 (según la cual la privación del derecho de voto para los condenados a una pena de más de dos años de reclusión es inconstitucional por violación del principio de proporcionalidad: el fin legítimo que el gobierno canadiense declaraba perseguir - una punición suplementar, que fomente la responsabilidad cívica y el estado de derecho - no convenció al Tribunal y porqué los medios utilizados por el gobierno no eran proporcionales al fin).

${ }^{206}$ Roach v. Electoral Commissioner, [2006] HCA 43, 2.5.2007, según el cual la privación del derecho de voto para todos los prisoneros condenados es inconstitucional, pero el legislador puede establecer la misma medida limitandola a los condenados a una pena de más de tres años.

207 Alrai v. Minister of the Interior HCJ 2757/06, 50(2) PD 18 [1996] (Isr.).

${ }^{208}$ La decisión del Tribunal Supremo de Estados Unidos Richardson v. Ramirez, 418 U.S. 24 (1974) es la menos recientes de las decisiones aquí citadas y quizá la única adoptada según un críterio de judicial self-restraint. No es una coincidencia que dicha decisión haya considerado constitucionalmente legítimas las fuertes limitaciones del derecho de voto previstas en varios estados miembros de Estados Unidos. El argumento central utilizado por Richardson v. Ramirez es que la sección 2 de la XIV enmienda a la Constitución, que menciona la privación del derecho de voto por las leyes estatuales «por participación en una rebelión o en otro crímen» permite a los estados de excluir los condenados del derecho de voto y excluye un control de la legislación estatal desde el punto de vista del respeto del principio de la equal protection fundada en la sección 1 de la misma XIV enmienda. Sin embargo, en el fallo Hunter v. Underwood, 471 US 222, 233 (1985) el Tribunal supremo declaró inconstitucional una norma de la Constitución de Alabama que había quitado el derecho de voto a las personas condenadas por crímenes de moral turpitude, aun si dichos crímen no eran sancionados con la carcel. El Tribunal supremo opinó que dicha norma, aun si construida formalmente de manera neutral desde el punto de vista racial, había sido en realidad adoptada con finalidades discriminatorias. Para una exposición de los fallos mas recientes sobre este tema se v. M.E. Feinberg, Suffering Without Suffrage: Why Felon Disenfranchisement Constitutes Vote Denial Under Section Two of the Voting Rights Act, in Hastings Poverty and Law Journal, 8:2 (2011), p. 61 y ss.

${ }^{209}$ Se vean, entre otros, las decisiones del Tribunal Electoral del Poder Judicial de la Federa-

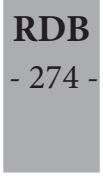


una importante corriente jurisprudencial elaborada en el sistema de protección de derechos humános del Consejo de Europa.

Estas sentencias se sitúan al interior de un doble conflicto: el entre los jueces supremos o constitucionales y las Asambleas representativas democraticamente elegidas - que en varios casos introducieron ${ }^{210}$ o confirmaron ${ }^{211}$ la privación del derecho de voto de los condenados - y el entre los tribunales nacionales y los supranacionales, en los casos en los cuales la privación del derecho de voto de los condenados tenía un fundamento constitucional interno ${ }^{212}$.

ción en los fallos SUP-JDC-20/2007, SUP-JUD 98/2010 y SUP-JDC-157/2010. Sobre estos fallos v. nuestro comentario en M. Olivetti, Presunción de inocencia, custodia cautelar y limitaciones al sufragio pasivo, ponencia en el III Observatorio Judicial Electoral, Ciudad de México, 2011 y L. Ríos Vega, La suspensión preventiva del sufragio pasivo: ¿prisión, libertad o proporcionalidad?, Documento de Trabajo para el III Seminario Internacional del Observatorio Judicial Electoral, TEPJF, Ciudad de México, 2010.

${ }^{210}$ Es por ej. el caso de Australia (2006) y de Nueva Zelanda [si v. l'Electoral (Disqualification of sentenced prisoners) Amendment Act 2010, que insertó la letra (d) en el art. 80.1 del Electoral Act 1983, bajo el cual no tiene derecho de voto «a person who is detained in a prison pursuant to a sentence of imprisonment»]. Sobre este último caso, se v. la opinión crítica de A. Geddis, Prisoner Voting and Rights Deliberation: How New Zealand's Parliament Failed, en New Zealand Law Review, 2 (2011) pp. 454-455.

${ }^{211}$ Es por ej. el caso de Canadá y de Reino Unido, en el primer caso después de la primera sentencia Sauvé, en el Segundo después de la sentencia Hirst del TEDH. Sobre el debate parlamentario en la Cámara de Comunes británica de febrero 2011 (v. House of Commons, Debates, vol. 523, col. 493), al final del cual dicha asamblea rechazó la modificación del Representation of the People Act 2000 pedida por el TEDH se v. D. Nicol, Legitimacy of the Commons Debate on Prisoner Voting, en Public Law, oct. 2011, p. 681 y ss. Sin embargo, en noviembre 2012 el Lord Chancellor publicó el Draft Voting Eligibility (Prisoners) Bill y anunció el nombramiento de un Joint Committee de las dos Cámaras, encargado de proceder al pre-legislative scrutiny. El borrador de proyecto de ley imagina tres soluciones: la solución A y la B reconocen el derecho de voto a todo los que estan espiando penas de prisión respectivamente de meno de 4 años o 6 meses, rientra que la solución C confirmaría la exclusión completa del voto de todos los prisoneros condenados. El 18 de diciembre de 2013 el Joint Committee publicó un Informe en el cual se afirma: «we recommend that the Government introduce a Bill at the start of the 2014-15 session, which should provide that all prisoners serving sentences of 12 months or less should be entitled to vote in all UK parliamentary, local and European elections; and moreover that prisoners should be entitled to apply, up to 6 months before their scheduled release date, to be registered to vote in the constituency into which they are due to be released». Para el informe ahora citado se v. http://www.publications.parliament.uk/pa/jt201314/jtselect/jtdraftvoting/103/10302.htm.

${ }^{212}$ Además, en varios estados miembros los Tribunales constitucionales o supremos se han pronunciado sobre el tema en examen en el contesto generado por la jurisprudencia del TEDH: se vea por ej. las decisiones del Tribunal constitucional de Austria de 27.11.2003 y de 27.9.2007 y el Tribunal supremo del Reino Unido en $R$ (on the application of Chester) $v$ Secretary of State for Justice y McGeoch (AP) $v$ The Lord President of the Council and another (Scotland), del 16.10.2013.

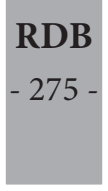


En su conjunto, la jurisprudencia ha desplazado la perspectiva del análisis de este tema - sitúado «at the intersection of voting rights and criminal justice» ${ }^{213}$ - del derecho penal al derecho constitucional, internacional y electoral. Sin embargo, en esta modificación de perspectiva se ha producido una desvalorización de las razones que justificaban $-\mathrm{y}$ que a nuestro parecer pueden seguir justificando ${ }^{214}-$ la restricción del derecho de voto.

En este ensayo se analizará la evolución de la jurisprudencia del Tribunal europeo de derechos humanos, que ha adoptado varias decisiones sobre este tema entre 2004 y 2013, dando orígen a un "recorrido jurisprudencial" no siempre linear y todavía no acabado. Después de una breve introducción sobre la colocación sistemática del derecho de voto y de los derechos políticos en el sistema del Convenio europeo de los derechos humanos (parr. 2 y 3 ) se analizarán las limitaciones a dicho derecho y en particular la que consigue a una condena penal definitiva (par. 4). Entonces se analizará la jurisprudencia del TEDH sobre el derecho de voto de los prisoneros condenados, evidenciando sus elementos de continuidad y sus contradiciones (par. 5-8) y se intentará una crítica general de las posiciones prevalentes en ella (par. 9).

\section{Los derechos políticos en el Convenio Europeo de Derechos Huma- NOS: LAS LIBERTADES DE REUNIÓN Y DE ASOCIACIÓN}

Los derechos de participación política estan situados al margen del corpus principal de los derechos fundamentales garantizados por el CEDH, que en su texto originario, se presentaba como una codificación limitada a los derechos clásicos de libertad, en el sentido estricto de esta noción, es decir como limitado a los Abwehrrechte (derechos de defensa), o libertades negativas. En comparación con estas últimas, los derechos de participación política constituyen una categoría de derechos distintos, cuya característica común es la de permitir a los ciudadanos de participar a la formación de la voluntad del estado ${ }^{215}$ : entonces entre las libertades clásicas y los derechos políticos hay la distancia identificada por Benjamin Constant entre las

\footnotetext{
${ }^{213}$ A.C. Ewald, "Civic death": the ideological paradox of criminal disenfranchisement law in the United States, en Wisconsin Law Review, 2002, p. 1054.

${ }^{214} \mathrm{Si}$ v. infra, par. 9.2.

${ }^{215}$ Arndt, Art. 3, ZP 1, in U. Karpenstein, F.C. Mayer (a cura di), EMRK - Konvention zum Schutz der Menschenrechte und Grundfreiheiten - Kommentar, Verlag C.H. Beck, München, 2012, p. 390 subraya que se trata de un „Teilhaberecht“ y que el art. 3 del Prot. Ad. n. 1 requiere que los estados adopten medidas positivas. El TEDH, en el fallo Sitaropoulos and Giakoumopoulos v. Greece [GC], App. no. 42202/07, § 67, 15.3.2012 comentó que «In the context of Article 3 of Protocol No. 1, the primary obligation is not one of abstention or non-interference, as with the majority of civil and political rights, but one of adoption by the State of positive measures to "hold democratic elections"». Sobre el voto como status activus civitatis se v. G. Jellinek, System der subjektiven öffentlichen Rechte, Mohr, Tübingen, 1905, pp. 136 y ss. y 159 ss.
} 
libertades de los modernos y las libertades de los antiguos.

Sin embargo, la participación de los ciudadanos a la vida política no es un fenómeno extraneo al Convenio, en primer lugar por las razones historico-políticas que el 4 de noviembre de 1950 fueron a la base del Convenio mismo: la de ofrecer una síntesis de los derechos de la tradición liberal-demócrata de Europa Occidental, como alternativa sea a los fascismos derrotados en la segunda guerra mundial, sea a los régimenes comunistas entonces triunfantes en la Europa del Este bajo dominación soviética. La importancia de la democracia representativa y, por reflexo, de los derechos de participación política que este tipo de régimen político supone, se percibe, en el texto originario del Convenio, por lo meno en dos aspectos: de un lado la referencia a una sociedad democrática como contexto en el cual se situan los derechos garantizados por el Convenio ${ }^{216}$; de otro lado la inclusión, entre los derechos protegidos por el $\mathrm{CEDH}$, de unas libertades que desarrollan un papel de «puentes» entre las libertades privadas y la participación a la vida política: es el caso de los derechos de reunión y asociación, garantizados por el art. 11 del CEDH, cuya proyección política deriva de su carácter de derechos individuales de libertad con a ejercicio colectivo. $\mathrm{Si}$ es cierto que las libertades de reunión y de asociación son relevantes tambien en la perspectiva de la vida privada y social (pero "pre-política) de las personas (como se vé en la explicita mención en el art. 11 de la libertad de asociación en sindicatos), es tambien claro que dichas libertades - así como la libertad de opinión protegida por el art. 10 - permiten al ciudadano, y a los ciudadanos organizados, de influir en la esfera pública y en la vida política. Esta relevancia «pública» de los derechos protegidos por el art. 11 es confirmada por la jurisprudencia del TEDH, que incluye la libertad de asociación en partidos políticos entre las diferentes formas de la libertad de asociación protegida por el Convenio. El Tribunal ha subrayado que dicho perfíl de la libertad de asociación goza de una protección reforzada, con la consecuencia que en las limitaciones a la libertad de los partidos los Estados miembros disponen de un margen de apreciación más estricto ${ }^{217}$.

\footnotetext{
${ }^{216}$ Véase el Preámbulo (cf. Zdanoka v. Latvia - GC, App. 58278/00, dec. 16.3.2006, § 98 y ss) y los art. 9.2, 10.2 y 11.2 del CEDH.

${ }_{217}$ United Communist Party of Turkey v. Turkey, App. 133/1996/752/951, 30.1.1998, § 46. Sin embargo, según el TEDH tampoco este perfíl de la libertad de asociación es exente de limites y los partidos que persiguen un programa político incompatible con los valores democráticos consagrados en el Convenio pueden ser disueltos por los estados miembros (Refah Partisi et al. C. Turquie, Req. 41340/98, 41342/98, 41343/98 et 41344/98, dec. 13.2.2003 § 100, 102 y ss.; Herri Batasuna et Batasuna c. Espagne, Req. 25803/04 et 25817/04, dec. 30.6.2009 § 63-64, 78, 82).
} 


\section{LA GARANTÍA DE ELECCIONES LIBRES Y SECRETAS}

En el sistema jurídico del Convenio europeo de los derechos humanos el derecho de voto (es decir el más importante de los derechos de participación política) es objeto de una regulación escrita solo gracias al primer Protocolo adicional al Convenio, firmado en Paris el 20 de marzo de 1952 y entrado en vigor el 18 de mayo de 1954. Y además esta regulación se refiere al derecho de voto solo en forma indirecta: el artículo 3, de hecho, no adopta la perspectiva más amplia que se encuentra en la Declaración universal de los derechos humanos de 1848 (art. 21) ${ }^{218}$, en el Pacto Internacional de los derechos civiles y políticos de 1966 (art. 25) ${ }^{219}$, en el Convención Americana sobre derechos humanos de 1969 (art. 23) $)^{220}$ y en la Carta africana sobre los derechos humanos y de los pueblos (art. 13) 221 $^{22}$ que todos garantizan el derecho de participar a la dirección de los asuntos públicos, el derecho de votar y de ser votado y el derecho al igual acceso a las funciones públicas de su propio país. Al contrario, el art. 3 del I Protocolo Adicional contiene una formulación más restrictiva ${ }^{222}$ :

${ }^{218}$ 1. Toda persona tiene derecho a participar en el gobierno de su país, directamente o por medio de representantes libremente escogidos. 2. Toda persona tiene el derecho de acceso, en condiciones de igualdad, a las funciones públicas de su país. 3. La voluntad del pueblo es la base de la autoridad del poder público; esta voluntad se expresará mediante elecciones auténticas que habrán de celebrarse periódicamente, por sufragio universal e igual y por voto secreto u otro procedimiento equivalente que garantice la libertad del voto.

219 Todos los ciudadanos gozarán, sin ninguna de la distinciones mencionadas en el artículo 2, y sin restricciones indebidas, de los siguientes derechos y oportunidades: a) Participar en la dirección de los asuntos públicos, directamente o por medio de representantes libremente elegidos; b) Votar y ser elegidos en elecciones periódicas, auténticas, realizadas por sufragio universal e igual y por voto secreto que garantice la libre expresión de la voluntad de los electores; c) Tener acceso, en condiciones generales de igualdad, a las funciones públicas de su país.

${ }^{220}$ 1. Todos los ciudadanos deben gozar de los siguientes derechos y oportunidades: a) de participar en la dirección de los asuntos públicos, directamente o por medio de representantes libremente elegidos; b) de votar y ser elegidos en elecciones periódicas auténticas, realizadas por sufragio universal e igual y por voto secreto que garantice la libre expresión de la voluntad de los electores, y c) de tener acceso, en condiciones generales de igualdad, a las funciones públicas de su país. 2. La ley puede reglamentar el ejercicio de los derechos y oportunidades a que se refiere el inciso anterior, exclusivamente por razones de edad, nacionalidad, residencia, idioma, instrucción, capacidad civil o mental, o condena, por juez competente, en proceso penal.

${ }^{221}$ Todo ciudadano tendrá derecho a participar libremente en el gobierno de su país, ya sea de modo directo o a través de representantes libremente escogidos de conformidad con las disposiciones de la ley. 2. Todo ciudadano tendrá derecho a acceder al servicio público de su país. 3. Todo individuo tendrá derecho a acceder a la propiedad y a los servicios públicos en estricta igualdad con todas las personas ante la ley.

${ }^{222}$ F. Sudre, Droit international et européen des droits de l'homme, VII ed., Puf, Paris, 2005, 
Las Altas Partes Contratantes se comprometen a organizar, a intervalos razonables, elecciones libres con escrutinio secreto, en condiciones que garanticen la libre expresión de la opinión del pueblo en la elección del cuerpo legislativo.

Formalmente, entonces, el art. 3 no utiliza la expresión derecho de votar»y por esto no parecería posible razonar de una garantía del derecho subjetivo de votar y de ser votado.

La naturaleza de la garantía contenida en el art. 3 del Protocolo Adicional n. 1 es en primer lugar objetiva: las Altas Partes Contratantes se comprometen a organizar elecciones libres. Aparentemente esta parecía ser solo una obligación recíproca de los Estados miembros y no un derecho individual de los ciudadanos: entonces de un lado este artículo podría quizá compararse a las cláusulas de homogeneidad políticas previstas en las Constituciones de los Estados federales, con la finalidad de harmonizar las estructuras políticas de los estados miembros ${ }^{223}$. De otro lado, este artículo parecería tener relevancia solo en el marco del procedimiento de garantía colectiva previsto por el Convenio, es decir de los procedimientos entre $\operatorname{estados}^{224}$ y no en el marco del recurso individual.

De hecho, las primeras decisiones de la Comisión europea de derechos humanos ${ }^{225}$ habían interpretado el artículo 3 del Prot. Ad. como una garantía institucional y no como un derecho subjetivo y habían afirmado que dicho artículo no garantizaba el derecho individual de votar, sino solo el derecho a que los Estados pp. 478-479.

${ }^{223}$ El ejemplo más conocido es la garantía a los Estados miembros de una forma de gobierno republicana, prevista por el art. IV, sec. 4 de la Constitución de Estados Unidos. Cláusulas similares se encuentran también en la Constitución suiza (art. 5), en la argentina (art. 5) y en la alemana (art. 28). Sobre este problema se v. M. Olivetti, Nuovi statuti e forma di governo delle Regioni. Verso le Costituzioni regionali?, Il Mulino, Bologna, 2002, p. 44 y ss.

${ }^{224}$ S. Marcus-Helmons, Article 3, en L.-E. Petitti, E. Decaux, P.-H. Imbert (dir.), La Convention européenne des droits de l'homme, II ed., Economica, Paris, 1999, p. 1013, que cita como exemplo la demanda de Dinamarca, Noruega, Suecia y Holanda contra Grecia en 1969 por violación de este artículo después del golpe de estado de 1967.

${ }^{225}$ Hasta la modificación del Convenio con el Protocolo n. 11 (que fue adoptado el 11 de maio de 1994 y entró en vigor el $1^{\circ}$ de noviembre de 1998), la Comisión Europea de Derechos Humanos era el organo al cual se sometian sea las demandas de los estados sea las demandas individuales, estas últimas solo en el caso de que el estado miembro afectado hubiese aceptado especificamente este procedimiento, que entonces era facultativo. Después de la decisión de la Comisión, el asunto podía llegar al Tribunal, lo que, sin embargo, pasaba solo en un número limitado de casos. F. Sudre, Droit européen, cit., p. 534 recuerda que el Tribunal adoptó 36 sentencias entre 1960 y 1979, 119 sentencias entre 1980 y 1989 y 389 sentencias entre 1994 y 1998, es decir, en este último periodo, un promedio de 75 sentencias cada año, es decir más que en todo el período 1959-82. 
miembros organizacen elecciones libres ${ }^{226}$ y que las elecciones libres mencionadas por el art. 3 implicaban el sufragio universal ${ }^{227}$.

No era entonces cierto que fuese posible desumir del art. 3 del Prot. Ad. n. 1 un derecho subjetivo. Sin embargo, ya en 1975 la Comisión europea de los derechos humanos había llegado a la conclusión que dicho artículo garantiza un derecho subjetivo individual ${ }^{228}$ y el TEDH, en el caso Mathieu-Mohin, en 1981, el primero en el cual se ocupó del art. 3, confirmó y desarrolló esta orientación.

Mientras que todas las demás claáusulas normativas del Convenio y de los Protocoles n. 1, 4, 6 y 7 (P1, P4, P6, P7) utilizan palabras como Toute personne a droit» o Nul ne peut», el artículo 3 (P1-3) utiliza la expresión Les Hautes Parties Contractantes s'engagent». Tal vez se ha deducido de esto que el art. 3 no crea de derchos y libertades individuales "directamente reconocidas a todos los que» que estan sometidos a la jurisdicción de dichas partes (sentencia Irlanda contra Reino Unido del 18 de enero de 1978, série A no 25, p. 91, § 239), sino que crea unicamernte obligaciones entre estados. [...] Una interpretación tan restrictiva no resiste a l'examen [...]. Los trabajos preparatorios del Convenio no revelan ninguna intención de excluir, en el campo del art. 3 (P1-3), el juego del derecho individual, mientras que se piensó por mucho tiempo de excluir el control de la Corte. Además, en los trabajo preparatorio se encuentran frecuentes menciones de la libertad política, de los derechos políticos», de los derechos y libertades políticas del individuo, del derecho a elecciones libres y del derecho de voto.

Entonces ... la «coloración interestadual» de la formulación del artículo 3 (P1-3) no reflete ninguna diferencia de fondo con las demás cláusulas normativas del Convenio y de los Protocoles. Ella parece explicable con la voluntad de dar más solemnidad a la tarea asumida y con la circumstancia que en el campo considerado se encuentra en primer plano no una obligación de abstención o de non interferencia, como por la mayoría de los derechos civiles y políticos, sino la obligación, a cargo del estado, de adoptar medidas positivas para “organisar" elecciones democráticas» ${ }^{229}$.

\footnotetext{
${ }^{226} \mathrm{Si}$ v. i casi decisi dalla Corte sulla base di Req. 530/59 e 1065/61 X and others v. Belgium, Com. Dec. 18.9.1961. Sobre la evolución de la jurisprudencia de la Comisión y del Tribunal se v. C. Pinelli, Protocollo 1 - Art. 3, en S. Bartole, B. Conforti, G. Raimondi (cur.), Commentario alla Convenzione europea per la tutela dei diritti dell'uomo e delle libertà fondamentali, Cedam, Padova, 2001, pp. 847 y ss.

${ }^{227}$ X. v. Federal Republic of Germany, App. 2728/66, dec. 6.10.1967.

${ }^{228}$ W., X, Y et Z. Contre Belgique, Req. 6745/74 y 6746/74, dec. 30.5.1975.

${ }^{229}$ Mathieu Mohin et Cleyrfaut c. Belgique, Req. 9267/81, dec. 2.3.1987, n. 48-50; Zdanoka v. Latvia, n. 102.
} 
Se trata de una interpretación extensiva del texto del art. 3 del Prot. Ad. n. 1 , que parece discutible sea desde el punto de vista literal, sea desde el punto de vista histórico, sea desde el punto de vista sistemático ${ }^{230}$.

En lo que concierne a la letra del art. 3, es claro que no hay ninguna mención de la dimensión subjetiva de la garantía de elecciones libres y aun menos de un derecho individual de voto.

En lo que se refiere a los trabajos preparatorios ${ }^{231}$, el TEDH puede encontrar en ellos solo referencias genéricas a los derechos políticos y puede hacer hincapié unicamente sobre un argumento «negativo», según el cual no había ninguna intención de excluir el recurso individual.

Por fin, el sistema de los derechos garantizados por el CEDH autoriza una conclusión diferente de la a la cual llegó el TEDH, en primer lugar por la naturaleza misma de los derechos políticos, que son al mismo tiempo una forma de participación del ciudadano a una función pública, antes de ser un derecho subjetivo individual. Y el texto del art. 3 se refiere a dichos derechos exactamente en esta perspectiva, considerando los intereses individuales en este ámbito como reflexos de una garantía objetiva, la de elecciones libres. En otras palabras: el art. 3 reconoce el derecho de voto para realizar elecciones libres, no el revés (es decir: no reconoce las elecciones libres para permitir a la dignidad de la persona de exprimirse en el voto).

Sin embargo, estas observaciones tienen solo la función de subrayar que lo que explica la "subjetivización" del derecho de voto es el activismo judicial del TEDH y no el texto del CEDH y de sus protocolos, interpretados según las reglas tradicionales de la hermenéutica jurídica. Se trata, entonces (como en muchos otros aspectos de la jurisprudencia de los jueces de Estrasburgo), de actos de voluntad y no de razón y el derecho individual de votar y de ser votado es entonces un derecho descubierto por la Corte europea, de creación «pretoria» ${ }^{232}$. De toda manera, es difícil negar hoy que la jurisprudencia del TEDH sobre la existencia en el art. 3 de un derecho subjetivo de votar y de ser votado se haya consolidado y el jurista positivo tiene que aceptar este hecho consumado.

\footnotetext{
${ }^{230}$ De hecho aun al final de los años noventa un autor comentaba que el reconocimiento de un derecho subjetivo individual de voto era «le point le plus étonnant» de la jurisprudencia de la Comisión y del Tribunal: S. Marcus-Helmons, Article 3, cit., p. 1020.

${ }^{231}$ Sobre el origen del art. 3 se v. R. Goy, La garantie européenne du droit à des libres élections législatives: l'article 3 du premier Protocole additionnel à la Convention de Rome, en Revue du droit public et de la science politique, 1986, p. 1278 y ss.

${ }^{232}$ F. Sudre, Droit international et européen, cit., p. 482 y 484.
} 


\section{LAS limitaciones del derecho de Voto COMPATIBLES CON EL CONVENio Y EL PROBLEMA DE LOS CONDENADOS A UNA PENA DE PRISIÓN}

A) En su jurisprudencia, el TEDH subraya constantemente la importancia central de este derecho en el sistema del Convenio europeo de derechos humanos. Sin embargo, también en este caso, la jurisprudencia de Estrasburgo repite su afirmación clásica, según la cual el derecho de voto no es absoluto ${ }^{233}$ y los estados pueden limitar los derechos garantizados por el artículo 3 por varios tipos de finalidades:

Los derechos garantizados por el artículo 3 del Protocolo no 1 sono muy importantes para la creación y la preservación de una verdadera democracia fundada sobre la prevalencia del derecho. Sin embargo, dichos derechos no son absolutos. Hay margen para «limitaciones implicitas», y a los Estados contractantes debe reconocersele un margen de apreciación en la materia $^{234}$.

Según el TEDH, la ausencia de una enumeración de los motivos de las limitaciones deja a los Estados miembros un margen de apreciación más extenso de lo que pasa en los derechos - como los de reunión y de asociación - en los cuales el Convenio mismo menciona las razones por las cuales los estados pueden limitar el derecho en cuestión ${ }^{235}$.

En una decisión reciente el TEDH ha llegado a comentar que:

Given that Article 3 of Protocol No. 1 is not limited by a specific list of "legitimate aims", the Contracting States can justify a restriction by reference to any aim which is compatible with the principle of the rule of law and with the general objectives of the Convention ${ }^{236}$.

Considerado que en su estructura textual el articulo 3 no menciona el derecho de voto, no puede sorprender que dicho artículo tampoco mencione las finalidades por las cuales se permiten las limitaciones de dicho derecho.

Las restricciones están sometidas al respeto del principio de proporcionalidad, es decir:

1) tiene que perseguir un fin legítimo;

\footnotetext{
${ }^{233}$ M. Starita, Art. 3 Prot. Ad. n. 1, en S.Bartole, P. De Sena, V. Zagrebelsky (a cura di), Commentario breve alla Convenzione europea dei diritti dell'uomo, Cedam, Padova, 2012, p. 842.

${ }^{234}$ Zdanoka c. Lettonie, n. 98 y 103.

${ }^{235}$ Zdanoka c. Lettonie, n. 86. Se vea M. Starita, Art. 3 Prot. Ad. n. 1, cit., p. 834.

${ }^{236}$ Shindler v. The United Kingdom, App. 19840/09, dec. 7.5.2013, n. 101
} 
2) tienen que ser necesarias para conseguir el fin;

3) no deben existir alternativas menos restrictivas para el titular del derecho.

El Tribunal de Estrasburgo ha subrayado que los derechos de votar y de ser votado no deben ser limitados en su misma sustancia» ni privados de su efectivi$\operatorname{dad}^{237}$. El TEDH utiliza un criterio más estricto en el control sobre las limitaciones al derecho de votar que sobre las al derecho a ser votado. El margen de apreciación nacional, ya amplio en el derecho de votar, es aún más amplio en el derecho de ser votado.

B) La jurisprudencia de la Comisión de derechos humanos permitía inicialmente que algunas categorías de personas, como los encarcelados por ejecución de una condena penal, fueran privadas del derecho de $\operatorname{votar}^{238}$. En el fallo $X$. v. Federal Republic of Germany, la Comisión había afirmado que la restricción del derecho de voto de convicted prisoners serving their sentence... do not affect the «free expression of the opinion of the people in the choice of the legislature» within the meaning of Article 3 of the Protocol (P1-3)

Y en el fallo H. v. The Netherlands, la misma Comisión había afirmado que

Este tipo de limitaciones se explican con la idea que unas condenas marcan de infamia para un periodo determinado que puede ser tenido en consideración por la legislación en lo que se refiere al ejercicio de los derechos políticos. Aún si puede parecer rígido que una condena superior a un año tenga siempre como consecuencia una suspensión del derecho de voto por tres años, la Comisión no cree que una medida de este tipo exceda las limitaciones que pueden ser justificadas en el marco del artículo 3 del Protocolo Adicional ${ }^{240}$.

Hay que subrayar que en el fallo que se acaba de citar la condena de la cual derivaba la suspensión del derecho de votar era una condena por rechazo de prestar el servicio armado por una persona que no había respetado las formalidades previstas en la ley para ser calificado como objetor de conciencia: entonces sin dudas una condena por un crimen de relevancia menor. Ademas, en la decisión que se acaba de

\footnotetext{
${ }^{237}$ Matthews v. The United Kingdom, App. 24833/94, dec. 18.2.1999, n. 65, Labita c. Italie, Req. 26772/95, dec. 6.4.2000, n. 201.

${ }^{238}$ X v. Federal Republic of Germany, App. 2728/66, dec. 6.10.1967. Nello stesso senso si v. Xv. United Kingdom, App. 7730/76, dec. 28.2.1979.

${ }^{239}$ X v. Federal Republic of Germany, App. 2728/66, dec. 6.10.1967. Nello stesso senso si v. Xv. United Kingdom, App. 7730/76, dec. 28.2.1979.

${ }^{240}$ H. v. The Netherlands, Req. 9914/82, dec. 4.7.1983.
} 
citar, la misma Comisión había reconocido

la existencia de un principio generalmente reconocido según el cual ciertas restricciones que se refieren al derecho de voto pueden ser impuestas a los condenados a ciertas penas de prisión ${ }^{241}$.

La Comisión había entonces llegado a la conclusión (que nos parece razonable) que las limitaciones del derecho de voto de este tipo no violaban el principio de elecciones libres y idoneas a permitir la libre expresión de la opinión del pueblo.

Aun recientemente, en el caso M.D.U. c. Italie, 28.1.2003, el TEDH había considerado que la suspensión por dos años del derecho de voto de una persona condenada por fraude fiscal, podía ser justificada por el fin de proteger the proper functioning and preservation of the democratic regime ${ }^{242}$ y no había considerado necesario proceder a un text detallado de proporcionalidad: al contrario, el TEDH había rechazado el recurso como manifestamente infudado. Esta tendencia a dejar un margen de apreciación bastante amplio a los estados fue abandonada en unos casos más recientes, que involucraron el Reino Unido, Romania, Austria y Italia, en los cuales el TEDH adoptó una interpretación mas restrictiva - y todavía muy discutida - que considera la restricción del derecho de voto como una regla muy problemática a la luz del art. 3 del Protocolo Adicional n. 1. Después de un parcial cambio de jurisprudencia en una sentencia de la Gran Cámara sobre un caso italiano, el criterio restrictivo adoptado por el TEDH se ha manifestado de nuevo en dos decisiones relativas a Rusia y a Turquía. Es entonces necesario examinar en el detalle los casos Hirst v. United Kingdom, Frödl v. Austria, Scoppola c. Italie y los casos de 2013: sobre el primero y el tercero de estos casos se ha pronunciado no solo una sala del Tribunal, sino también la Gran Cámara.

\section{LA JURISPRUDENCIA DEL TEDH SOBRE EL DERECHO DE VOTO DE LOS PRISONE- Ros: el Caso Hirst contra Reino Unido}

A) La sentencia Hirst representó un dramático cambio en comparación con la jurisprudencia anterior del TEDH: de hecho, todos los fallos sobre el derecho de voto de los condenados sucesivos a esta sentencia utilizan lor argumentos expuestos por primera vez en esta decisión, especialmente en la versión de la Gran Cámara, como base para la decisión, que, a su vez retoma unos argumentos de la sentencia Savué v. Canada (Chief Electoral Officer).

La legislación del Reino Unido establecía (y sigue estableciendo ${ }^{243}$ ) la suspensión del derecho de votar para todos los condenados a penas que consistan en la privación de la libertad personal, con la excepción de los condenados por contempt

\footnotetext{
${ }^{241}$ H. v. The Netherlands, Req. 9914/82, dec. 4.7.1983.

${ }^{242}$ Si. v. M.D.U. c. Italie, Req. 58540/00, dec. 28.1.2003, n. 14.

${ }^{243}$ Se vea supra nota 9.
} 
of the court y por no haber pagado una multa, y sin ninguna distinción basada en la gravedad del crimen. Al mismo tiempo, según la legislación británica, el disenfranchisement es una consecuencia automática y general de la condena, que opera sin intermediación del juez en la aplicación de la medida de la privación del derecho de voto. La legislación del Reino Unido incluye desde tiempos muy antiguos la privación del derecho de voto entre las consecuencias de la condena, y esta limitación fue confirmada por las leyes electorales que se adoptaron sucesivamente ${ }^{244}$. En 2000 dicha legislación había sido modificada, en cierta medida suavizandola, reconociendo el derecho de voto a las personas detenidas por enfermedades mentales en ausencia de una condena y a los detenidos todavía no condenados ${ }^{245}$.

En la decisión de primera instancia Hirst v. The United Kingdom (no. 2), del 30.3.2004, la IV sala del Tribunal consideró desproporcionada la legislación del Reino Unido. El TEDH confirmó su jurisprudencia, según la cual los derechos de votar y de ser votado son fundamentales pero no son absolutos y confirmó que los estados disponen de un margen de apreciación en el marco del cual pueden establecer limitaciones: pero dichas restricciones no pueden afectar a la substancia misma de los derechos de votar y de ser votado, ni privarlos de efectividad ${ }^{246}$. El TEDH ha reconocido que el margen de apreciación del cual disponen los estados en la reglamentación de las condiciones que rigen el derecho de voto depende también de la ausencia de un consenso en las normas y en las prácticas de los estados miembros ${ }^{247}$. Según el Tribunal, los estados tiene que utilizar este margen de apreciación intentando de realizar un balance entre el derecho de voto y las restricciones previstas por la ley; per el TEDH observó que en el Reino Unido las restricciones al derecho de voto nunca fueron objeto de un debate detallado ante los órganos legislativos con la finalidad de encontrar un equilibrio entre los intereses que estan en juego, y que dependan exclusivamente de una fidelidad a la tradicción histórica ${ }^{248}$.

Aplicando el test de proporcionalidad, el TEDH se ha preguntado en primer lugar si la restricción del derecho de voto persiguía un fin legítimo, y ha considerado como fines en abstracto admisibles de un lado la prevención del crimen y la

\footnotetext{
${ }^{244}$ La raíz se encuentra en la llamada «muerte civíl» (civic death) que consistía en la privación de unos derechos de un condenado desde los tiempos del Rey Eduardo III. Dichas limitaciones fueron confirmadas por el Forfeiture Act 1870 (sobre el cual W. Anson, The Law and Custom of the Constitution, vol. I, Parliament, V ed., Clarendon Press, Oxford, 1922, p. 131-132 comentaba que «conviction of treason or felony is a disqualification, unless either the term of punishment has been served or a free pardon has been obtained») y por el Representation of the People Act 1969.

${ }^{245}$ Representation of the People Act 2000, sec. 3.

${ }^{246}$ Hirst v. the United Kingdom (no. 2), App. 74025/01, n. 36.

${ }^{247}$ Hirst v. the United Kingdom (no. 2), n. 40. En el mismo sentido v. también Yumak and Sadak v. Turkey, App. 10226/03, 8.7.2008, n 109 e Communist Party of Russia and others v. Russia, App. 29400/05, dec. 19.6.2002, n. 109.

${ }^{248}$ Hirst v. the United Kingdom (no. 2), n. 41.
} 
punición de los reos y del otro en reforzamiento del sentido civico y el respeto del estado de derecho, con la consecuencia que las personas que comitieron graves violaciones de la ley penal pueden ser privadas del derecho de participar a la formación de estas reglas por el período de espiación de su pena ${ }^{249}$. Despues de haber analizado los argumentos de la Corte suprema de Canadá en los casos Sauvé 1 y Sauvé 2 (llegando a la conclusión que dichos argumentos pueden ser utilizados para el caso en examen ${ }^{250}$ ) el TEDH manifestó dudas sobre la legitimidad de los fines mencionados (subrayando que, a su parecer, la privación del derecho de voto no favorece la rehabilitación del condenado), pero preferió no adoptar una posición porqué le pareció que la aplicación del principio de proporcionalidad en sentido estricto fuera suficiente a resolver el caso $^{251}$.

En lo que se refiere a la proporcionalidad en sentido estricto, la Corte opinó que

la disposición en cuestión priva del derecho de voto, garantizado por el Convenio, una gran candidad de personal (más de 70 000) en forma indiscriminada. De hecho, ella establece una restricción global para todos los detenidos condenados con sentencia definitiva y se aplica automaticamnte a todos ellos, cual que sea la duración de su pena y independientemente de la naturaleza o de la gravedad de la violación que hayan cometido ${ }^{252}$.

B) El gobierno del Reino Unido pidió que la decisión de la IV sala del TEDH fuese remitida a la Grande Chambre del mismo Tribunal y dicha petición fue aceptada bajo el art. 43 del CEDH. Sin embargo, la Gran Cámara, en su sentencia Hirst v. the United Kingdom (no. 2) - GC, del 6.10.2005 confirmó en su esencia la decisión de la IV sala, aún si modificó unas argumentaciones, esencialmente aceptando la tesis del gobierno del Reino Unido sobre la existencia de un fin legítimo, pero considerando desproporcionadas las limitaciones del derecho de voto previstas para realizarlas. La decisión de la Gran Cámara fue adoptada con una mayoría de 12 votos contra 5 y los jueces disidentes redactaron dos votos particulares, que contestaron la decisión de la mayoría con argumentos de una cierta importancia.

La Gran Cámara describió en primer lugar el marco general en materia de derecho de voto de los prisoneros. El TEDH subrayó que los prisoneros guardan en general todos los derechos y libertades fundamentales garantizados por el Convenio, con la excepción del derecho de libertad y que todas las restricciones a dichos derechos tienen que ser justificadas, por ejemplo con exigencias de seguridad o de prevención del crímen ${ }^{253}$. La Gran Cámara excluyó de manera muy rotunda que el

\footnotetext{
${ }^{249}$ Hirst v. the United Kingdom (no. 2), n. 42.

${ }^{250}$ Hirst v. the United Kingdom (no. 2), n. 47.

${ }^{251}$ Hirst v. the United Kingdom (no. 2), n. 47.

${ }^{252}$ Hirst v. the United Kingdom (no. 2), n. 49.

${ }^{253}$ Hirst v. the United Kingdom (no. 2) - GC, n. 69.
} 
prisonero pierda sus derechos simplemente en consecuencia de su encarcelación y afirmó que no hay lugar en el sistema del Convenio por una privación automática del derecho de voto basada simplemente en lo que puede ofender a la opinión públi$\mathrm{ca}^{254}$. Los estandares de tolerancia del Convenio no impiden a la sociedad de adoptar medidas en contra de los que intentan de destruir los derechos garantizados por el Convenio mismo y las restricciones de los derechos electorales pueden ser adoptadas en contra de individuos que abusaron de un cargo público o que menazaron el estado de derecho o los fundamentos de la democracia ${ }^{255}$. Pero la medida del disenfranchisement puede ser adoptada solo si, bajo el principio de proporcionalidad, hay una conexión intelegible y suficiente entre la sanción y la conducta y las circumstancias del individuo afectado ${ }^{256}$.

A diferencia de la IV sala del TEDH, la Grande Chambre opinó que el fin perseguido por la legislación inglesa con la privación general del derecho de voto para los prisoneros condenados fuese finalizada a «prevenir el crimen sancionando la conducta de los prisoneros condenados y también de fortalecer la responsabilidad cívica y el estado de derecho» y aceptó esta finalidad como un fin legitimo en la perspectiva del principio de proporcionalidad ${ }^{257}$.

Sin embargo, el Tribunal llegó a la conclusión que la privación en via general del derecho de voto para todos los condenados a una pena de detención de más de 2 años era desproporcionada, sea porqué la ley británica no hacía (y no hace) distinciones entre condenas de diferente gravedad, sea en cuanto la misma ley se aplica en forma general y automática y no deja al juez ninguna evaluación sobre la aplicación de la suspensión del derecho de voto al caso concreto ${ }^{258}$.

En conclusión, el Tribunal definió la disciplina del Reino Unido como

un instrumento sin matices, que priva del derecho de voto, garantizado por el Convenio, un gran número de individuos, y de forma indiferenciada. Esta disposición inflige una restricción global a todos los detenidos condenados que estan espiando su pena y se aplica automaticamente a ellos, cual que sea la duración de su pena y independentemente de la naturaleza o de la gravedad de la infracción que hayan cometido y de su situación personal. Es necesario opinar que una restricción general, automática y indiferencia$\mathrm{da}$, de un derecho consegrado por el Convenio y que tiene una importancia crucial, va más allá del margen de apreciación acceptable, por ampio que sea, y es incompatible con el art. 3 del Protocolo no $1^{259}$.

\footnotetext{
${ }^{254}$ Hirst v. the United Kingdom (no. 2) - GC, n. 70.

${ }^{255}$ Hirst v. the United Kingdom (no. 2) - GC, n. 71.

${ }^{256}$ Hirst v. the United Kingdom (no. 2) - GC, n. 71.

${ }^{257}$ Hirst v. the United Kingdom (no. 2) - GC, n. 74-75.

${ }^{258}$ Hirst v. the United Kingdom (no. 2) - GC, n. 77.

${ }^{259}$ Hirst v. the United Kingdom (no. 2) - GC, n. 82.
} 
El TEDH, entonces, atribuyó una importancia central a la conexión entre la privación del derecho de voto y las circumstancias particulares del crimen cometido, retomando, también sobre este punto, un argumento del Tribunal Supremo de Canadá en el fallo Sauvé v. Canada (Chief Electoral Officer).

La Gran Cámara constató la ausencia de consenso sobre este tema entre los estados contractantes, y reconoció que los estados miembros tienen un margen de apreciación nacional amplio en la definición de las restricciones del derecho de voto, en particular para los prisoneros. Pero al mismo tiempo subrayó que dicho margen no es ilimitado ${ }^{260}$ y llegó a la conclusión que la privación automática del derecho de voto en consecuencia de una condena definitiva queda fuera de dicho margen. Peró reconoció que los estados pueden utilizar varias y diferentes medidas para hacer frente a la cuestión del derecho de los prisoneros de votar ${ }^{261}$.

La decisión de la Gran Cámara es interesante también por la opinión disidente de los jueces Wildhaber, Costa, Lorenzen, Kovler y Jebens, que formularon una crítica muy bien argumentada a la posición de la mayoría. En particular, los jueces disidentes afirmaron que «el Tribunal ha constantemente afirmado en su jurisprudencia que los estados contractantes benefician de un amplio margen de apreciación» en la materia del derecho de voto y que «el art. 3 del Prot. Ad. n. 1 prohibe las restricciones al derecho de voto que tengan naturaleza general, bajo reserva que no sean arbitrarias y no obstaculen la "la libera expresión de la opinión del pueblo", lo que pasa por ejemplo con las restricciones basadas sobre la edad, la nacionalidad o la residencia».

Contrariaemente a la mayoría nosotros no pensamos que una limitación general al derecho de voto de los detenidos tenga que ser evaluada en manera en principio diferente y hasta hoy la jurisprudencia de los órganos del Convenio nunca ha llegado a una conclusión diferente.

Nosotros no creemos tampoco que sea necesaria una decisión del juez en cada caso concreto. Al contrario, es evidentemente compatible con la garantía del derecho de voto que dicha cuestión sea resuelta en abstracto por el legislador ${ }^{262}$.

Según el voto particular, habría sido preferible una actitud inspirada a la prudencia:

Si las restricciones no afectan la substancia misma del derecho de voto y si no son arbitrarias, se debe declarar la legislación nacional sobre el derecho de voto incompatible con el art. 3 solo si de razones poderosas justifican

\footnotetext{
${ }^{260}$ Hirst v. the United Kingdom (no. 2) - GC, n. 83.

${ }^{261}$ Hirst v. the United Kingdom (no. 2) - GC, n. 84.

${ }^{262}$ Hirst v. the United Kingdom (no. 2) - GC, voto particular, n. 4.
} 
una conclusión de este tipo. Nosotros no creemos que razones de este tipo hayan sido formuladas ${ }^{263}$.

El voto particular considera que la interpretación adoptada por la mayoría en el caso Hirst es de tipo dinámico-evolutivo y que una interpretación de este tipo necesita de una base en cambios en las sociedades de los estados contratantes y una tendencia al consenso entre sus legislaciones. Esto es esencial porqué el Tribunal es un juez y no un legislador ${ }^{264}$.

En otro voto particular el juez Costa subraya que la decisión ha privado el estado contratante de todo margen de apreciación en un derecho (el derecho de voto) que es de creación jurisprudencial ${ }^{265}$.

\section{El caso Frodl v. Austria}

Las principales argumentaciones de la Grande Chambre en el caso Hirst fueron en seguida acceptados, y ulteriormente desarrollados, por la III sala del TEDH en el fallo Calmanovici c. Roumanie (1.7.2008) ${ }^{266}$ y por la I sala del mismo Tribunal el caso Frodl v. Austria (8.4.2010). Considerada la casi total identidad de argumentos en los dos fallos, se sintetizarán aquí solo los de la segunda de estas dos sentencias.

Según el sistema jurídico austriaco ${ }^{267}$, la privación del derecho de voto no se aplica a todos los condenados por violaciones de normas penales, sino solo a los condenados: a) con sentencia definitiva; b) por crímenes intencionales; c) a una pena de por lo meno un año de prisión (excluyendo las multas y las detención por meno de un año). Según el Tribunal constitucional de Austria, que se había pronunciado sobre la conformidad de este sistema al CEDH, estas limitaciones a la aplicación del disenfranchisement diferencian el sistema adoptado en Austria del sistema británico sancionado por la sentencia Hirst y permeten a la legislación austriaca de respetar el principio de proporcionalidad quedandose al interior del márgen de apreciación nacional ${ }^{268}$.

En su sentencia, la I sala del TEDH sintetizó la jurisprudencia ya elaborada en el caso Hirst sobre la existencia de un derecho individual de votar y la admisibi-

\footnotetext{
${ }^{263}$ Hirst v. the United Kingdom (no. 2) - GC, voto particular, n. 5.

${ }^{264}$ Hirst v. the United Kingdom (no. 2) - GC, voto particular, n. 5.

${ }^{265}$ Hirst v. the United Kingdom (no. 2) - GC, voto particular, n. 9.

${ }^{266}$ A conclusiones parecidas a las deCalmanovici v. Romania, App. 42250/02, dec. 10.2.2009, el TEDH llegó otra vez en el fallo Cucu v. Romania, App. 22362/06, 13.11.2012, en partic. N. 111.

${ }^{267}$ Art. 26 de la Constitución federal, art. 22 del Reglamento de la Asamblea nacional, art. 44 del codigo penal.

${ }^{268}$ Se v. las sentencias citadas supra en la nota 7.
} 
lidad de limitaciones a dicho derecho ${ }^{269}$, la contrariedad al Convenio de limitaciones que afecten a la esencia misma del derecho en cuestión ${ }^{270}$, la titularidad de los derechos por los condenados (los prisoneros en general guardan todos los derechos y libertades fundamentales garantizados bajo el Convenio, con la excepción del derecho de libertad) y la inaceptabilidad de un sistema en el cual la privación del derecho de voto sea una simple y automática consecuencia de una condena a una pena de prisión (bajo el sistema del Convenio, en el cual la tolerancia y la apertura mental son carácteres distintivos de una sociedad democrática, no hay ningun lugar para una privación automática del derecho de voto basada sólo en lo que puede ofender a la opinion pública ${ }^{271}$ ). Establecido este marco conceptual, el TEDH ha reconocido de nuevo la posibilidad de limitaciones al derecho de voto, pero a la condición que sea respetado el principio de proporcionalidad ${ }^{272}$.

El TEDH opinó que la limitación del derecho de voto de los prisoneros prevista por la legislación austriaca correspondía al fin legítimo de la prevención del crimen y del reforzamento de la responsabilidad cívica ${ }^{273}$, aceptando el argumento del gobierno de Austria, según el cual el sistema era más matizado y meno indiferenciado del sistema británico. Sin embargo, eso no fue suficiente porqué el Tribunal llegase a la conclusión que el sistema austriaco es compatible con el Convenio.

Citando su decisión en el caso Hirst, pero andando más allá de lo que había afirmado literalmente en aquel fallo, el TEDH individuó tres condiciones porqué la privación del derecho de voto de los condenados fuese compatible con el art. 3 del Protocolo Adicional n. 1:

1) La exclusion del derecho de voto puede ser prevista solo para un grupo estrictamente definido de condenados que estan espiando una condena de duración larga

2) es necesaria una connexion directa entre los hechos sobre los cuales la condena está basada y la sanción de la privación del derecho de voto

3) dicha medida tiene que ser dispuesta preferiblemente non como consecuencia directa de una ley, sino por la decisión de un juez después de un procedimiento judicial ${ }^{274}$.

La finalidad de dichos criterios, según el TEDH, es establecer que la privación del derecho de voto de los condenados - aún si es admisible - sea configurada

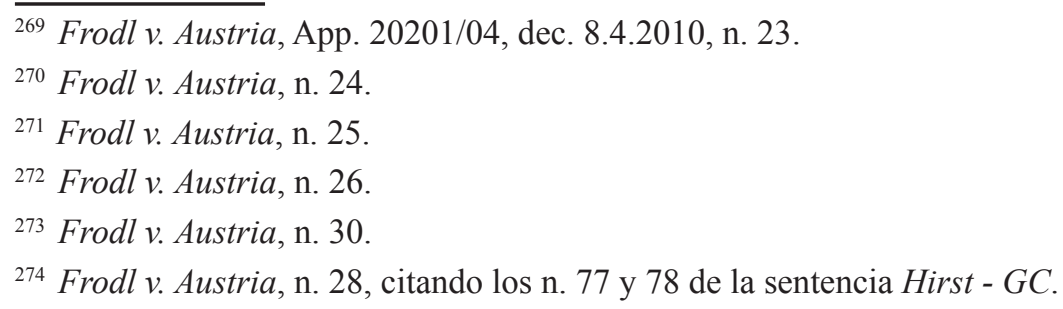


como una excepción y no como la regla ${ }^{275}$. Por esta razón,

es esencial que la decision sobre la privación del derecho de voto sea adoptada por un juez, tomando en cuenta las circumstancias específicas, y que exista una conexión entre el crimen cometido y asuntos relativos a elecciones y a instituciones democráticas.

Este argumento del Tribunal - que fue en seguida abandonado en la decisión de la Gran Cámara en el caso Scoppola-3 - fue expuesto de manera parecida también en el fallo Calmanovici:

el principio de proporcionalidad exige la existencia de una conexión visible y suficiente entre la sanción y el comporamento así como la situación de la persona afectada. El Tribunal consideró también la racomandación de la Comisión de Venecia según la cual la privación de los derechos políticos tiene que ser pronunciada por un juez en una decisión específica, porqué un tribunal independiente que utiliza un procedimiento contradictorio ofrece una buena garantía contra la arbitrariedad $[\ldots]^{276}$.

Este argumento, sin embargo, es discutible desde diferentes puntos de vista. Se introduce de esta manera una técnica que en la doctrina italiana se suele llamar reserva de jurisdicción, es decir se permite la limitación del derecho solo bajo previa y específica decisión judicial en el fallo concreto. En primer lugar hay que subrayar que el sistema del Convenio y la tradición constitucional y legislativa de los estados miembros no suportan una conclusión de este tipo: la necesidad que los derechos puedan ser limitados exclusivamente bajo una específica decisión judicial no es general, sino propia de unos derechos, como los de libertad personal, de domicilio, de correspondencia, de prensa, etc. (en el caso, por ejemplo, de la Constitución italiana).

De otro lado, la limitación del derecho de voto como consecuencia de una condena penal tiene a su origen de un lado una ponderación de intereses realizada por el legislador (que establece dicha consecuencia de una condena) y de otro lado de una decisión judicial sobre la aplicación de la ley al fallo concreto. La intervención preventiva del juez, que según el Tribunal desarrolla la función de garantizar el respeto del principio de proporcionalidad, ya es necesario para otorgar la sanción penal en el caso concreto y no es necesario preverlo también para la privación del derecho de voto que consigue a dicha sanción: si existe una exigencia de proporcionalidad, es entre unos tipos de crimenes y la privación del derecho de voto, pero a dicha exigencia puede hacerse frente con una ponderación de intereses realizada por el legislador in abstracto. Al contrario, una intervencion del juez lleva con sigo el riesgo de una evaluación caso por caso, con lesión del principio de igualdad, que en la limitación de los derechos políticos tiene que ser respetada de manera particu-

\footnotetext{
${ }^{275}$ Frodl v. Austria, n. 35.

${ }^{276}$ Calmanovici c. Roumanie, $\S 153$.
} 
larmente rigurosa, no solo en el interés de sú titular, sino también por exigencias de regularidad del proceso democrático, no solo en el interés de su titular, sino también por exigencias de regularidad del proceso democrático, a protección de las cuales esta puesto el art. 3 del Prot. Ad. n. 1.

Despuès de la sentencia en el caso Frodl, la República de Austria pidió que el fallo fuese remitido a la Gran Cámara, pero su petición fue declarada inadmisible por el Tribunal bajo el art. 44.2 del CEDH.

\section{El caso Greens y el Caso Scoppola 3}

A) En el caso Greens and M.T. v. The United Kingdom (22-11-2010), la IV sala del Tribunal volvió a pronunciarse sobre la legislación de Reino Unido, examinando los tentativos del gobierno británico de implementar la decisión de la Corte en el caso Hirst. El TEDH constató que los jueces británicos habían rechazado de dejar inaplicado (reading down) el art. 8 de la ley de 2002 sobre las elecciones de los representantes británicos en el Parlamento europeo, que establece la privación del derecho de voto de los condenados prevista por, y que además esta posibilidad no habría influenciado la prohibicción prevista por el Representation of the People Act 2000 para las elecciones nacionales ${ }^{277}$. El TEDH comentó que ningun cambio había sido introducido en la legislación británica y entonces constató la violación del Prot. Ad. n. $1^{278}$. Considerado que dicha prohibicción afectaba a un gran número de prisoneros condenados (en el n. 75 se cita la opinión de la Equality and Human Rights Commission, según la cual dicho número es de 100.000 electores), el Tribunal aplicó el procedimiento por los llamados juicios pilotas, porqué la violación del art. 3 tenía su origen en una situación normativa consolidada.

Subrayando la existencia de un amplio margen de apreciación que el Reino Unido podía utilizar para decidir como adecuar su ordenamiento jurídico a la jurisprudencia Hirst ${ }^{279}$, y evidenciado el retrazo del gobierno británico en la implementación de dicha jurisprudencia ${ }^{280}$, el TEDH no individuò soluciones específicas y estableció para la presentación de una propuesta de ley finalizada a modificar el art. 3 del Representation of the People Act 2000 y el art. 8 de la ley sobre la elección de los representantes británicos al Parlamento europeo un plazo de seis meses después de la fecha en el cual la sentencia Greens se habría convertido en definitiva ${ }^{281}$. El Tribunal decidió entonces de interrumpir el examen de todos los fallos parecidos que se refirían al Reino Unido, en los cuales se plantease la violación del art. 3 del Prot. Ad. n. $1^{282}$.

\footnotetext{
${ }^{277}$ Greens and M.T. v. The United Kingdom, App. 60041/08 and 60054/08, n. 69.

278 Greens and M.T. v. The United Kingdom, n. 78.

${ }^{279}$ Greens and M.T. v. The United Kingdom, § 113-114.

${ }^{280}$ Greens and M.T. v. The United Kingdom, $\S 105$.

${ }^{281}$ Greens and M.T. v. The United Kingdom, § 115.

${ }^{282}$ Greens and M.T. v. The United Kingdom, § 120-121.
} 
La petición del gobierno inglés de remitir el fallo ante la Gran Cámara fue rechazada por el panel del Tribunal el 11 de abril de 2011. Sin embargo, en agosto de 2011, el Tribunal mismo acceptó otra petición del gobierno británico de modificar la fecha para eliminar la violación estructural del Convenio establecida en la sentencia Greens, individuando como dies a quo del plazo de seis meses no el dia en el cual la sentencia sobre el caso Greens se había convertido en definitiva (el 11 de abril de 2011), sino el dia de la sentencia de la Gran Cámara en el caso Scoppola-3, sobre el cul la II sala del Tribunal acababa de decidir y acerca de cuya decisión el Tribunal mismo había aceptado la petición del gobierno italiano de remitir el fallo a la Grande Chambre. De esta manera el gobierno británico tenía otra oportunidad para exponer otra vez sus argumentos en dicho procedimiento ${ }^{283}$.

B) En el caso Scoppola contra Italia (n. 3), del 18.1.2011, la II sala del Tribunal tuvo la oportunidad de evaluar el sistema italiano de las llamadas «penas acesorias», entre las cuales está incluida la interdición de los cargos públicos, que tiene como consecuencia la privación del derecho de voto. Este sistema es en parte similar y en parte diferente del sistema inglés, porqué es menos automático y general y distingue entre tres hypótesis de base:

1) los crímenes sancionados con una condena de menos de tres años, por los cuales no hay privación del derecho de voto;

2) los crimenes sancionados con una condena por un período incluido entre un mínimo de tres años y un máximo de cinco, por los cuales se aplica la privación temporánea del derecho de voto por 5 años; $y$

3) los crimenes por los cuales es prevista una pena de más de cinco años, por los cuales se aplíca la privación perpetua del derecho de voto (se trata, entonces, de una forma de life disenfranchisement, que puede ser eliminada como consecuencia de la rehabilitación del condenado).

A estos tres casos puede añadirse el de los crimenes que, aun siendo sancionados con una pena de menos de tres años, fueron cometidos con abuso de poderes o con violación de los deberes que dependen de una función pública, por los cuales se aplica la interdición de los cargos públicos y entonces la privación del derecho de voto por un período igual a la duración de la pena, y la de los delitos electorales.

Entonces se puede afirmar que dicho sistema distingue entre casos más graves y casos menos graves, bajo un criterio de proporcionalidad. Sin embargo, el sistema italiano es por unos aspectos aun más radical del sistema inglés, porqué cuando se aplica la privación perpetua del derecho de voto, el condenado no recupe-

${ }^{283}$ A. Colella, La Grande Camera della Corte EDU nel caso Scoppola (n. 3): la disciplina italiana della decadenza dal diritto di voto dei detenuti non contrasta con l'art. 3 Prot. 1, in www.penalecontemporaneo.it, 28.5.2012. 
ra su derecho de votar ni tampoco después de la expiación de su condena ${ }^{284}$.

Otro perfil relevante en el caso Scoppola 3 es si en el sistema italiano se realiza una intervención caso por caso del juez en la aplicación de la pena acesoria de la privación del derecho de voto. Según la II sala del TEDH, es esencial que la decisión sobre la interdicción del derecho de voto sea adoptada por un juez y que sea adecuadamente motivada: esta decisión tiene que explicar especialmente las razones por las cuales, consideradas las circumstancias particulares de cada caso, la privación del derecho de voto es necesaria ${ }^{285}$.

El Tribunal concentró su análisis sobre la naturaleza automática de la limitación del derecho de voto, comentó que la cuestión que se plantea es de saber si la privación del derecho de voto presenta las características de generalidad y de automaticidad enumeradas por la Gran Cámara en el fallo Hirst c. Royaume-Uni (no 2) ${ }^{286}$ y llegó alla conclusión que

la interdicción perpetua del derecho de voto que ha afectado al apelante era una consecuencia de la aplicación de la pena acesoria de la interdicción de las funciones públicas. Esta última deriva automaticamente de la aplicación de la pena principal que consiste en la condena del apelante a la reclusión por la vida. Es entonces necesario constatar que la aplicación de la medida era de naturaleza automática. Hay que subrayar que, como observa el apelante, en las decisiones judiciales de condena del apelante no se hace ninguna mención de esta medida (n. 48).

En lo que se refiere a los carácteres de generalidad y de aplicación indiferenciada, el Tribunal comenta que el criterio establecido por la ley no tiene, en el caso concreto, que una naturaleza basada en la duración de la pena, porqué el apelante ha perdido el derecho de voto en consecuencia de la pena de privación de su libertad, independientemente del crimen cometido y de cualquier examen de juez de la causa sobre la naturaleza y la gravedad de esto (Frodl c. Austria, citado, $\S \S 34$ et 35). Según el Tribunal, en este contexto, la evaluación del juez al momento de la determinación de la pena y la posibilidad por la persona condenada de obtenir en futuro su rehabilitación ... no modifican esta constatación.

La legislación italiana fue entonces considerada en contraste con el art. 3 del Prot. Ad. n. 1 por la modalidad automática con la cual la interdición de los cargos públicos produce sus efectos, y en particular por la falta de una decisión judicial específica en la implementación de dicha medida en los fallos concretos.

${ }^{284}$ Este segundo aspecto de la legislación italiana es subrayado correctamente por el juez David Thór Björgvinsson en la decisión de la Gran Cámara en el caso Scoppola 3.

${ }^{285}$ Scoppola v. Italy (no. 3), App. 126/05, dec. 18.1.2011, n. 43.

${ }^{286}$ Scoppola v. Italy (no. 3), n. 47. 
C) Después de la sentencia de la II sala en el fallo Scoppola-3, el gobierno italiano pidió que el fallo fuese remitido a la Gran Cámara y - a diferencia de lo que había pasado en los casos Frodl y Greens - su petición fue aceptada bajo el art. 43.3. del CEDH.

La decisión de la Gran Cámara en el caso Scoppola-3 es un primer paso atraz en la jurisprudencia de la Corte sobre la privación del derecho de voto de los condenados, que en los casos Hirst, Calmanovici, Frodl y Scoppola 3 (II sala) había conocido un desarrollo hasta entonces linear, si no expansivo. Como ya se decía, en este fallo la Grande Chambre tuvo que hacer frente no solo a la petición del gobierno italiano, sino tambien a una intervención del gobierno del Reino Unido, que había pedido una revisión de la jurisprudencia Hirst. Además, la decisión llegó en un contexto en el cual el gobierno británico había criticado varias veces el activismo del Tribunal y había propuesto, en el período de su presidencia de rotación del Consejo de Europa, de modificar al CEDH para subrayar con mayor claridad su papel subsidiario respecto a los sistemas nacionales de protección de los derechos y para añadir en el Preámbulo al Convenio la mención expresa del margen de apreciación nacional (dichas propuestas son mencionadas también en la llamada Declaración de Brighton $)^{287}$.

La Gran Cámara no abandonó las posiciones tomadas en Hirst, pero las interpretó de manera restrictiva y procedió a un overruling de un punto central de los casos Calmanovici y Frodl: la necesidad de la intervención previa de un juez para privar un condenado del derecho de voto. En el punto 99 de su decisión en el caso Scoppola-3 (GC) se afirma:

El Tribunal subraya que la decisión en el fallo Hirst no menciona explicitamente la intervención de un juez entre los criterios esenciales para determinar la proporcionalidad de una medida de privación del derecho de voto. Los criterios relevantes se refieren solo a si la medida es aplicable de manera general, automática y indiscriminada [...]. Si la intervención de un juez es en principio adapta a garantizar la proporcionalidad de restricciones a los derechos de votos de los prisoneros, dichas restricciones no son necesariamente automáticas, generales y indiscriminadas solo porqué no han sido ordenadas por un juez. De hecho, las circumstancias en las cuales una persona es privada del derecho de voto pueden ser specificadas por la ley, condicionando su aplicación a factores como la naturaleza o la gravedad de la ofensa cometida.

${ }^{287} \mathrm{Su}$ queste vicende v. D. Tega, I diritti in crisi. Tra Corti nazionali e Corte europea di Strasburgo, Giuffrè Editore, Milano, 2012, p. 139 ss. Rileva il nesso fra la decisione della Grande Chambre e la posizione assunta dall'opinione pubblica inglese sul diritto di voto dei detenuti anche A. Colella, La Grande Camera, cit. 
Modificando la decisión de la II sala, la Gran Cámara ha entonces llegado a la conclusión que la privación del derecho de voto sin una decisión judicial ad hoc no causa, en sí, una violación del art. 3 del Protocolo n. $1^{288}$.

Según la Gran Cámara, las distinciones previstas por la legislación italiana entre los casos en los cuales se limita el derecho de voto de los condenados muestran la preocupación del legislador italiano de matizar la aplicación de la medida a las circumstancias particulares del caso concreto, tomando en consideración factores como la gravedad de la ofensa cometida y la conducta del ofensor. Entonces, según la Corte, el sistema italiano no tiene el carácter general y automático que caracteriza el sistema británico, sea porqué los condenados por ofensas de menor gravedad no pierden el derecho de voto, sea porqué se toma en cuenta las circumstancias en las cuales los delitos fueron cometidos y la personalidad del condenado. Sin embargo, cabe subrayar que tampoco en el sistema italiano existe una relación entre el tipo de crimen cometido y la suspensión del derecho de voto y que el poder de ponderación del juez existe solo para los crimenes de menor entidad. Entonces la exigencia de proporcionalidad, sobre la cual el TEDH insiste mucho, es respetada solo dando de este principio una interpretación muy generica y minimal y, sobre todo, claramente diferente de la acogida en el caso Hirst, en el cual el Tribunal había considerado esencial la existencia de una conexión entre el tipo de delito cometido y la privación del derecho de voto y la ponderación entre delito y pena acesoria al momento de la condena ${ }^{289}$. De hecho, si se acepta la perspectiva del caso Hirst, la decisión de la Gran Cámara en el caso Scoppola-3 parece más una marcha atráz que una confirmación de la jurisprudencia anterior.

\section{Las decisiones de 2013: los casos Firth, Anchugov and Gladkov y SÖYLER}

Después del parcial overruling de su propria jurisprudencia en el caso Scoppola-3 el TEDH ha tenido la oportunidad de volver sobre el asunto del derecho de voto de los condenados en tres circumstancias diferentes.

A) En primer lugar queda pendiente la situación de Reino Unido. El Parlamento británico, hasta la fecha, ha rechazado una modificación de su sistema de privación general y automática del derecho de voto. Los jueces británicos adoptaron unas declaraciones de incompatibilidad entre el Representation of the People Act $\mathrm{y}$ el Human Rights Act, pero seguiron aplicando la ley británica, bajo el principio de la soberanía del Parlamento. El mismo Tribunal supremo del Reino Unido, en una

\footnotetext{
${ }^{288}$ Scoppola v. Italy (no. 3) - GC, n. 104.

${ }^{289}$ Subraya la diferencia entre los criterios de proporcionalidad adoptados en el caso Hirst y los del caso Scoppola-3 GC E.C. Lang, A Disproportionate Response: Scoppola v. Italy (No. 3) and Criminal disenfranchisement in the European Court of Human Rights, en American University International Law Review, 28:3 (2013), pp. 854-855.
} 
decisión muy reciente ${ }^{290}$, aun aceptando los principios desarrollados en el caso Hirst como interpretación correcta del art. 3 del Protocolo Adicional n. 1 (y rechazando una petición del gobierno de declarar que la interpretación adoptada por el TEDH no era compatible con dicha disposición), no aceptó las demandas de unos apelantes que pidían el reconoscimiento de su derecho de votar. Y el TEDH, en el fallo Firth and 2353 others vs. United Kingdom (12.3.2013) ha por el momento decidido de renviar el examen de otras controversias contra el gobierno británico fundadas en el art. 3 del Prot. Ad. n. 1.

En la segunda mitad de 2013, sin embargo, el TEDH ha vuelto sobre el asunto en dos casos que conciernen respetivamente a Rusia y Turquía, en los cuales ha constatado de nuevo la violación del art. 3 del primer Protocolo adicional.

B) En el caso Anchugov and Gladkov v. Russia (4.7.2013), la I sala del Tribunal ha analizado otra vez el tema en su conjunto y ha considerado que el sistema de privación del derecho de voto previsto en general para los condenados en Rusia es parecido al sistema británico ${ }^{291}$ y es por lo tanto incompatible con el Convenio porqué no respeta el principio de proporcionalidad. En particular, el TEDH ha considerado que no es relevante que la gravedad de la ofensa cometida sea tomada en cuenta por el Tribunal que adopta la sanción penal de la cual consigue la privación del derecho de voto, porqué no hay ninguna prueba que, cuando deciden si una sentencia de reclusión tiene o no tiene que ser impuesta, los jueces tomen en cuenta que dicha sentencia determinará la privación del derecho de voto ${ }^{292}$. Según el TEDH, hace falta, en el sistema ruso, sea de una intervención judicial en la aplicación de la medida de la privación del derecho de voto, sea de disposiciones legislativas que diferencien entre los diferentes $\operatorname{casos}^{293}$. En particular, la sala repite en forma nueva una de las afirmaciones que caracterizan esta jurisprudencia del TEDH (y que nos parecen totalmente infundadas: se vea infra, par. 9.2):

In the light of modern-day penal policy and of current human rights standards, valid and convincing reasons should be put forward for the continued justification of maintaining such a general restriction on the right of prisoners to vote as that provided by art. $32 \S 3$ of the Russian Constitution.

Además, el caso Anchugov and Gladkov es interesante porqué el TEDH analiza la cuestión de la relación entre una norma constitucional interna y el Convenio y llega a la conclusión que la naturaleza constitucional de la norma que establece

\footnotetext{
${ }^{290} \mathrm{Se} v$. la sentencia en los casos $R$ (on the application of Chester) $v$ Secretary of State for Justice y McGeoch (AP) v The Lord President of the Council and another (Scotland), del 16.10.2013.

291 Anchugov and Gladkov v. Russia, App. 11157/04 e 15162/05, dec. 4.7.2013, n. 101.

292 Anchugov and Gladkov v. Russia, n. 106.

${ }^{293}$ Anchugov and Gladkov v. Russia, n. 107.
} 
la privación del derecho de voto de los condenados - en este caso el art. 32.2 de la Constitución Rusa - es irrelevante ${ }^{294}$. Sobre este punto hay una contradicción: el TEDH subraya que según el derecho internacional los estados no pueden justificar la falta de cumplimiento de una norma de un tratado con el argumento que existe una norma constitucional que lo impide, pero de hecho ningun estado miembro del Consejo de Europa ha asumido la obligación de permitir a los condenados de votar: esta obligación no deriva del Convenio, sino de una opción jurisprudencial (muy discutible) del TEDH ${ }^{295}$.

La petición del gobierno ruso de remitir el fallo ante la Grande Chambre fue rechazada por el panel del Tribunal el 9 de diciembre de $2013^{296}$ y la sentencia es por lo tanto definitiva.

C) En el caso Söyler v. Turkey (17.9.2013), el TEDH ha llegado a la conclusión que también el sistema turco de privación del derecho de voto de los condenados está en contraste con el art. 3 del Protocolo Adicional n.1, porqué las limitaciones que establece no respetan el principio de proporcionalidad. En el sistema jurídico turco, el disenfranchisement afecta a todos los condenados a una pena de prisión que hayan cometido crímenes intencionales: en comparación con la privación general del derecho de voto por todas las personas encarceladas, originariamente previsto por la Constitución de 1982, hay dos excepciones al disenfranchisement de los prisoneros: los prisoneros en espera de juicio y los condenados por crímenes no intencionales.

Según la I sala del TEDH, la distinción prevista en la legislación turca entre crímenes a los quale consigue el disenfranchisement y crímenes (los más graves) por los cuales esta consecuencia no se produce no es suficiente para producir la diferenciacion entre los diversos tipos de delitos que es necesaria para que el principio de proporcionalidad, como interpretado por el mismo TEDH, sea respetado. El Tribunal llegó a esta conclusión utilizando una pluralidad de criterios: la ausencia de intervención de un juez (aún si la misma sala precisa no es un criterio esencial ${ }^{297}$ ); la restricción del derecho de voto no toma en consideración la gravedad del crimen ni las circumstancias individuales en las cuales fue cometido ${ }^{298}$. Como en el caso Frodl, la limitación del disenfranchisement a los crímenes intencionales no fue considerada suficiente por la I sala, con el argumento que «el gobierno no ha intentado de explicar como y porqué la exclusión de todas las personas condenadas por crímenes intencionales sería compatible con las finalidades perseguidas por el

\footnotetext{
${ }^{294}$ Anchugov and Gladkov v. Russia, n. 111.

${ }^{295}$ Esto es muy claro en los puntos de las decisions en los cuales se reconstruyen los "principios" que regulan el derecho de voto de los condenados: el TEDH es obligado a mencionar solo sus sentencias, porqué este criterio es de orígen unicamente jurisprudencial: véase Söyler v. Turkey, App. 29411/07, dec. 17.9.2013,n. 31.

${ }^{296}$ Se v. el Press Release del 10 dicembre 2013.

297 Söyler v. Turkey, n. 39.

${ }^{298}$ Söyler v. Turkey, n. 41.
} 
art. 3 del Protocolo adicional I» ${ }^{299}$.

En Söyler reaparecieron unos argumentos que habían sido marginalizados en Scoppola-3 GC: la gravedad del crimen (la sala comparó el delito cometido por Söyler con el cometido por Scoppola subrayando que en el caso en examen el crimen era mucho meno grave ${ }^{300}$ ), la conexión racional entre la sanción de la privación del voto y la conducta y la circumstancia del apelante ${ }^{301}$.

El disenfranchisement turco aparece al TEDH una medida automática y indiscriminada ${ }^{302}$, más duro y extensivo que los previstos en Austria, Italia y Reino Unido $^{303}$.

D) En su conjunto, entonces, la jurisprudencia de Estrasburgo sobre el derecho de voto de los presos es bastante contradictoria. Los estados miembros del Consejo de Europa pueden quitar el derecho de voto a los presos condenados en forma definitiva, poqué la limitación del derecho de voto es justificada por el fin legítimo de la prevención del crimen, del fortalecimiento de la responsabilidad cívica y del respeto del estado de derecho. Sin embargo, dicha limitación, para respetar el principio de proporcionalidad en sentido estricto, no puede ser general: el legislador tiene que prever una distinción entre los casos en los cuales a la condena penal sigue la privación del derecho de voto y los casos en los cuales esta consecuencia no se produce. La distinción, pues, tiene que ser articulada y no puede limitarse a distinguir entre los crímenes intencionales y los no intencionales. La intervención de un juez que establezca en concreto la privación del derecho de voto es una modalidad que el Tribunal considera idonea para asegurar el respeto del principio de proporcionaldiad, pero no es necesaria en todos los casos. Sobre este último punto, el paso atráz del Tribunal con la sentencia de la Grande Chambre en el caso Scoppolav. Italy-3 $G C$ ha añadido flexibilidad al sistema de vínculos construidos por el TEDH (y ha entonces ampliado el margen de apreciación nacionale), pero ha atenuado la coherencia de dicha jurisprudencia, cuyo elemento central parece ahora ser esencialmente la exclusión de la automaticidad entre la condena a la carcel y la privación del derecho de voto, por contraste con el principio de proporcionalidad.

Este punto de llegada de la jurisprudencia del TEDH nos parece discutible: pero es ahora necesario situar a esta crítica al exterior de la jurisprudencia misma, que hasta ahora hemos examinado solo desde el punto de vista de su coherencia interior.

\footnotetext{
${ }^{299}$ Söyler v. Turkey, n. 42.

${ }^{300}$ Söyler v. Turkey, n. 44.

${ }^{301}$ Söyler v. Turkey, n. 45.

302 Söyler v. Turkey, n. 47.

${ }^{303}$ Söyler v. Turkey, n. 38.
} 


\section{NotACIONES CRÍTICAS}

Después del análisis de los casos, en los cuales se ha intentado de poner en evidencia la evolución de la jurisprudencia, limitando a unas cuestiones específicas las observaciones críticas, es oportuno formular unas consideraciones de conjunto sobre la privación del derecho de voto de los prisoneros condenados desde un punto de vista de teoría constitucional, en cierta medida «exterior» a las argumentaciones adoptadas por el TEDH (en el sentido de independiente de las opciones de política de los derechos fundamentales adoptadas por el Tribunal mismo). Esta perspectiva mueve de la idea que entre las tareas de la doctrina exista la de una vigilancia crítica hacia las opciones de valores, ideológicas o políticas de los órganos jurisdiccionales, especialmente cuando estas sean basadas en actitudes activistas (judicial activism) y se muevan fuera de las tradiciones legislativas y constitucionales consolidatas.

\subsection{Críticas de MÉTodo}

Toda la jurisprudencia del TEDH sobre el derecho de voto de los condenados tiene características criticables en primer lugar por ser abstracta y autoreferencial.

En toda esta jurisprudencia falta un estudio detallado de las constituciones nacionales. Estas constituciones, como Cartas de derechos, son parte esencial del patrimonio constitucional europeo y no pueden ser reducidas a simple objeto de evaluación del Tribunal de Estrasburgo, como si fueran una ley cualquiera o un reglamento municipal. Si se analizan las constituciones escritas europeas, la regulación del derecho de voto muestra una apertura a la posibilidad de limitaciones del derecho de voto por varias razones específicas, que en unos casos son dejadas simplemente a las opciones del legislador ${ }^{304}$, mientras que en otros casos son mencionadas explicitamente. Y no es infrecuente encontrar, entre las causas mencionadas por la Constitución bajo las cuales la ley es autorizada o vinculada a limitar el derecho de voto, la condena penal irrevocable: es el caso del art. 54.2-a de la Constitucion de Holanda de $1983^{305}$, del art. 48 de la Constitución italiana de $1947^{306}$, del art. 32.3. de

\footnotetext{
304 Art. 16 de la Constitución de Irlanda de 1937, art. 49 de la Constitución de Portugal de 1976, art. 61 de la Constitución de Bélgica de 1993, art. 38.2 de la Constitución de Moldavia de 1991, art. 20 de la Constitución de la República Checa de 1992, que deja al legislador la determinación de las condiciones adicionales para el exercicio del sufragio

305 2. Est privé du droit de vote: a. celui qui, pour avoir commis une infraction spécifiée à cet effet par la loi, a été, par une décision judiciaire irrévocable, condamné à une peine privative de liberté d'au moins un an et déchu en même temps du droit de vote; (...).

3064 . El derecho de voto no puede sufrir limitaciones sino por motivos de incapacidad civil o por efecto de sentencia penal firme o en los supuestos de indignidad moral especificados por la ley.
} 
la Constitución de la Federación Rusa de 1993 ${ }^{307}$, del art. 29.1 de la Constitución de Dinamarca de $1953^{308}$, del art. 53.1 de la Constitución de Luxemburgo de 1868 (en el texto que resulta de la revisión de $1989^{309}$ ), del art. 51.3 de la Constitución de Grecia de $1975^{310}$, del art. 26.5 de la Constitución de Austria de 1920 ${ }^{311}$, del art. 64.c Constitución de Chypre de $1962^{312}$, del art. 62.2. de la Constitución de Polonia de $1991^{313}$, del art. 34.2 de la Constitución de Rumania de $1991^{314}$, del art. 65 de la Constitución de Bulgaria de 1991 ${ }^{315}$, del art. 58 de la Constitución de Estonia de 1991316, del art. 58 de la Constitución de Malta ${ }^{317}$ y del art. 67.5, I cláusula, de la Constitución de Tur-

307 (...) citizens detained in a detention facility pursuant to a sentence imposed by a court shall not have the right to vote or to stand for election.

308 1. Est électeur au Folketing toute personne de nationalité danoise qui a fixé son domicile dans le Royaume et qui a atteint l'âge requis pour l'exercice du droit de vote comme prévu au paragraphe 2 ci-dessous, à moins que cette personne n'ait été interdite. Une loi déterminera dans quelle mesure une condamnation pénale et des subventions qualifiées par la loi de secours de l'Assistance publique entraineront la déchéance du droit de vote.

${ }^{309} \mathrm{Ne}$ peuvent être ni électeurs ni éligibles: $1^{\circ}$ les condamnés à des peines criminelles; $2^{\circ}$ ceux qui, en matière correctionnelle, sont privés du droit de vote par condamnation; (...).

310 3. The Members of Parliament shall be elected through direct, universal and secret ballot by the citizens who have the right to vote, as specified by law. The law cannot abridge the right to vote except in cases where a minimum age has not been attained or in cases of legal incapacity or as a result of irrevocable criminal conviction for certain felonies.

${ }^{311}$ Forfeiture of the right to vote and to stand for election can only ensue from a court sentence.

${ }^{312}$ A person shall be qualified to be a candidate for election as a Representative if at the time of the election that person - (...) (c) has not been, on or after the date of the coming into operation of this Constitution, convicted of an offence involving dishonesty or moral turpitude or is not under any disqualification imposed by a competent court for any electoral offence; (...).

313 (2) Persons who, by a final judgment of a court, have been subjected to legal incapacitation or deprived of public or electoral rights, shall have no right to participate in a referendum nor a right to vote.

314 (2) Mentally deficient or alienated, laid under interdiction, as well as persons disenfranchised by a final decision of the court cannot vote.

315 (1) Tout citoyen bulgare qui n'a pas d'autre nationalité, a 21 ans révolus, n'est pas mis sous tutelle et ne purge pas une peine de privation de liberté peut être élu député.

316 The participation in elections of Estonian citizens who have been convicted by a court of law and who are serving a sentence in a place of detention may be restricted by law.

317 Section 58 [Disqualification from Voting] - «No person shall be qualified to be registered as a voter for the election of members of the House of Representatives if - (a) he is interdicted or incapacitated for any mental infirmity by a court in Malta or is otherwise determined in Malta to be of unsound mind; (b) he is under sentence of death imposed on him by any court in Malta or is serving a sentence of imprisonment (by whatever name called) exceeding twelve months imposed on him by such a court or substituted by competent authority for 
quía (en el texto modificado en 2001) ${ }^{318}$. Considerando la relevancia de este material constitucional en su conjunto, sorprende que el TEDH lo haya ignorado, y lo haya considerado solo como un problema y no come una llave para llegar a la solución. Bajo el examen del derecho constitucional nacional, el TEDH habría tenido que ver en la condena penal irrevocable una condición subjetiva que impide, en principio, el ejercicio del derecho de voto, con la excepción de los casos en loa cuales los estados decidan de manera diferente. De las constituciones nacionales parece de hecho posible desprender que la privación del derecho de voto de los condenados puede ser interpretada sea como una forma de protección de la democracia ${ }^{319}$ (o - para ser más exactos - de la representación política) ante litteram, sea como una consecuencia necesaria de la naturaleza de la institución de la carcel.

Una actitud más «histórica»y respetuosa de las tradiciones constitucionales nacionales ${ }^{320}$ habría evitado al TEDH de gastar inutilmente mucho tiempo (y dinero público) sobre una cuestión - la sobre el pretendido derecho de voto de los condenados - que ha sido creada en abstracto por una orientación jurisprudencial del Tribunal mismo, tomando como base discutibles decisiones judiciales de unos países de common law y que no tiene bases suficientes ni en el texto del Convenio, ni en las tradiciones constitucionales comunes de los estados miembros. No se trata solo de subrayar la existencia de un margen de apreciación nacional amplio, que el mismo Tribunal reconosce sobre este asunto, aún sin mucha claridad en la definición de su extensión. Se trata de reconstruir el alcance de los derechos garantizados por el Convenio utilizando las constituciones nacionales como instrumento de delimitación de la discrecionalidad y del arbitrio del TEDH. En fin, el de los «prisoners" voting rights» es un tema en el cual muy frecuentemente los jueces supremos han intentado de imponer una visión ideologica de los derechos fundamentales a los equilibrios historicamente consolidados de los estados liberales-demócratas contemporáneos y a sus textos constitucionales: se trata de un ámbito privilegiado del activismo judicial.

some other sentence imposed on him by such a court, or is under such a sentence of imprisonment the execution of which has been suspended; or (c) he is disqualified for registration as a voter by or under any law for the time being in force in Malta by reason of his having been convicted of any offence connected with the election of members of the House of Representatives.

318 Privates and corporals serving in the armed services, students in military schools, and convicts in penal execution excluding those convicted of negligent offences cannot vote.

${ }^{319}$ Nos referimos al concepto de orígen alemana de wehrhafte Demokratie o de democracia protegida.

${ }^{320}$ Ignorando la tradición constitucional en favor de una razón abstracta construida ex nihilo por los mismos jueces (apoyandose, en este caso, sobre decisiones judiciales adoptadas en los últimos diez años), el TEDH se priva de la posibilidad de utilizar la sabiduría que en el pasar de las décadas, y en unos casos (Reino Unido) de los siglos, se ha depositado en las normas $\mathrm{y}$ en las instituciones que crearon la misma cultura de los derechos humanos que el Tribunal tendría que fomentar. 


\subsection{Para una justificación teórica plausible de la privación del dere- CHO DE VOTO DE LOS CONDENADOS}

En los casos analizados en este ensayo se mencionaron varios tentativos de justificación de las normas que, en muchos sistemas jurídicos, prohiben a los condenados a la pena de la reclusión, o a los condenados por crímenes especialmente graves, o por unos tipos de crímenes, el ejercicio del derecho de voto. Y se analizaron las objecciones que el TEDH ha opuesto a muchos de estos tentativos de justificación, que en su forma de juzgar juegan el papel del fin legítimo que justifíca la limitación del derecho en la perspectiva del principio de proporcionalidad.

Concluyendo este ensayo, es oportuno intentar de explicar porqué la exclusión del derecho de voto de los prisoneros condenados nos parece en general justificada: y esto no solo en la perspectiva de derecho positivo (es decir, en este caso, en el intento de interpretar el art. 3 del Prot. Ad. n. 1) que se ha adoptado en los parrafos anteriores, sino en una perspectiva de teoría constitucional.

A nuestro parecer, la solución más coherente con una buena teoría de los derechos fundamentales es la adoptada por el Representation of the People Act 1983 del Reino Unido y aún más por el artículo 32.2 de la Constitución de la Federación Rusa de 1993: es decir la prohibicción de votar para todos los condenados, por el período en el cual se purga la condena y, en caso de crímenes de especial gravedad, quizá por toda la vida.

La primera razón que sugiere de adoptar esta perspectiva es la mencionada en varias defensas de los gobiernos acusados en los casos estudiados en este ensayo $^{321}$ : es fuertemente oportuno que las personas que violaron la ley penal, y que la violaron en manera tan grave que fueron condenados a una pena de prisión, no puedan participar a la elección de los órganos representativos, que tienen, entre otras cosas, el poder de definir la orientación política del país y de aprobar las normas más importantes que componen sus ordenamientos jurídicos, las de rango legislativo (y entre ellas las normas penales). Se trata de un argumento que es compatible sea con concepciones políticas de corte liberal ${ }^{322}$, sea con interpretaciones republicanas ${ }^{323} \mathrm{de}$ la política y de la democracia. La tesis según la cual este sería un objetivo «indefinido y simbólico», formulada con un eceso de arogancia intelectual por el Tribunal Supremo de Canadá en el fallo Sauvé ${ }^{324}$, es ahora rechazada en las sentencias del

${ }^{321}$ Cf. por ej. Calmanovici c. Roumanie, $\S 148$. Pero este argumento se encuentraba ya en la posición del gobierno canadiense en Sauvé v. Canada (Chief Electoral Officer).

${ }^{322}$ A.C. Ewald, "Civic death, cit., p. 1072 ss., que cita entre las autoridades liberales Locke, Rousseau, Paine y - con unas cautelas - el mismo Rawls (nota 148).

${ }^{323}$ A.C. Ewald, "Civic death”, cit., p. 1082 ss.

${ }^{324}$ Cf. Sauvé v. Canada (Chief Electoral Officer), § 16 e 22. Non parecen, al contrario indefinidas y no demostradas las tesis, contenidas en dicha sentencia, según las cuales to deny 
TEDH discutidas en este ensayo ${ }^{325}$.

Es verdad que - como afirma en varias sentencias el TEDH - la condena a la prisión no priva los condenados de todos los derechos fundamentales, pero no es exacto que ellos guardan todos los derechos compatibles con la reclusión: los derechos que guardan son los que son expresión de su dignidad humana, que no puede en ningun caso ser vulnerada ${ }^{326}$, pero ellos pierden, por el período de la detención los derechos de participar a la vida social, en consecuencia de la naturaleza de la cárcel como institución separada de la sociedad ${ }^{327}$ : los derechos de reunión y de asociación, y en general los derechos de participación política ${ }^{328}$. Es su igual dignidad social, y no su dignidad humana, que es comprimida como consecuencia de la condena. Solo individuos libres, que puedan discutir, asociarse, reunirse en público pueden ejercer razonablemente el derecho de voto ${ }^{329}$. Desde esta perspectiva, la posición adoptada por el Tribunal Constitucional de Sudáfrica en 1999, según la cual «the vote of each and every citizen is a badge of dignity and personhood», si es cierto que puede explicarse con la historia de aquel País, no es aceptable como afirmación de teoría

prisoners the right to vote is to lose an important means of teaching them democratic values and social responsibility e the negative effects of denying citizens the right to vote would greatly outweigh the tenuous benefits that might ensue. Denying prisoners the right to vote imposes negative costs on prisoners and on the penal system. It removes a route to social development and undermines correctional law and policy directed towards rehabilitation and integration.

${ }^{325}$ Esto es muy claro, aun si dichas sentencias llegan a conclusiones diferentes de las aceptadas en este ensayo por una utilización no correcta del test de subsidiariedad.

${ }^{326}$ El Tribunal constitucional italiano, en la sentencia n. 349 de 1993 afirmó que quien se encuentra en un estado de detención, aun si es privado de la mayor parte de su libertad, guarda siempre un residuo de la misma, que es especialmente importante porqué constituye el último ámbito en el cual puede desarrollarse su personalidad individual.

327 En este sentido M. Ruotolo, Diritti dei detenuti e Costituzione, Giappichelli, Turin, 2002, p. 163 (pero el autor, aun constatando el estado actual del derecho objetivo, exprime su esperanza que dicha separación sea reducida o eliminada).

328 Para este comentario se v. P. Ramsay, Faking Democracy with Prisoners' Voting Rights, LSE Law, Society and Economy Working Papers 7/2013, p. 9 (http://eprints.lse. ac.uk/48985/1/WPS2013-07_Ramsay.pdf).

${ }^{329}$ Este argumento fue propuesto por el gobierno ruso en el caso Anchugov and Gladkov (v. n. 89), pero fue ignorado por la I sala del TEDH. 
constitucional $^{330}$. Es claro que eso no significa que el voto sea un privilegio ${ }^{331}$ y no un derecho: solo significa que el voto es un derecho cuya titularidad y cuyo exercicio dipende de determinados supuestos, como la edad, la ciudadanía, en unos casos la residencia ${ }^{332}$ y de la ausencia de requisitos negativos, entre los cuales está tradicionalmente la condena a una pena de prisión.

Si es cierto que el derecho de voto es un un derecho individual, es también verdad que se trata de un derecho cuyo ejercicio tiene que ser necesariamente colectivo, como los derechos de reunión y de asociación: el voto, como acto individual y aislado, no tiene sentido, de la misma manera en la cual no tiene sentido una reunión o una asociacion a la cual participe solo una persona. La dialéctica del derecho de voto - bien sintetizada por Carl Schmitt en su Teoría de la Constitución ${ }^{333}$ - incluye ambas estas dos «polaridades»: la liberal y la demócrata, o, dicho con otra palabras, la individual y la social. No se trata de un «derecho de defensa», como los clásicos derechos de libertad, que son reconocidos a sus titulares porqué hagan de ellos el uso que más le agrade, sinó por el ejercicio de una función pública: el derecho de voto no solo es de ejercicio colectivo, sino es también un derecho funcional. Es entonces fisiológico que las personas a las cuales no es permitido desarrollar una vida social normal, como consecuencia de una sentencia que los haya condenados a la privación de la libertad personal, no sea permitido tampoco votar ${ }^{334}$.

\footnotetext{
${ }^{330}$ Según M.Á. Presno Linera, Ed derecho de voto, Tecnos, Madrid, 2003, p. 143 el que cumple una condena privativa de libertad no carece de capacidad para autodeterminarse políticamente y, además, esa circunstancia no convierte a quien se encuentra en ella en una persona carente de dignidad, por lo que la sanción consistente en la privación del sufragio activo por ese motivo no es en absoluto compatible con el mandato contenido en el artículo 25.2 de la Constitución». Sin embargo, a nuestro parecer, la capacidad de autodeterminación política es estructuralmente limitada por la institución de la carcel. Es exacto que el que se encuentra en la condición de privación de libertad no pierde su dignidad humana, pero el derecho de voto no es una consecuencia inmediata de esta última, como resulta del hecho que la titularidad de dicho derecho depende de varios requisitos ulteriores respecto a la capacidad jurídica.

${ }^{331}$ El argumento según el cual el voto es un derecho y no un privilegio es utilizado con frecuencia sea en la jurisprudencia, sea en la doctrina (ad es. A.W. Powers, Hirst, cit., p.2) para llegar a la conclusión que los condenados gozan de este derecho.

${ }^{332}$ Se v. la decisión de la Grande Chambre del TEDH en el fallo Sitaropoulos and Giakoumopoulos v. Greece, App. n. 42202/07, dec. 15.3.2012, en el cual se excluye que la falta de medidas que permitan a los ciudadanos residentes en el exterior de votar sea en contraste con el art. 3 del Prot. Ad. n. 1 (y en el mismo sentido v. Shindler v. The United Kingdom, § 114). ${ }^{333}$ C. Schmitt, Verfassungslehre (1928), tr. fr., Théorie de la Constitution, Presses Universitaires de France, Paris, 2008, pp. 383-384.

${ }^{334}$ En la cultura liberal contemporanea la justificación de la privación del derecho de voto de los condenados a una pena de prisión parece muy difícil (veanse los argumentos en este sentido de A.C. Ewald, "Civic death", cit., p. 1096 y ss.). Sin embargo, a nuestro parecer, esta dificultad depende de la explusión del concepto de responsabilidad individual de la cultura liberal de los derechos.
} 
Además, es necesario someter a crítica otra afirmación repetida muchas veces en varias sentencias del TEDH, según la cual la exclusión del derecho de voto de los prisoneros condenados afectaría al principio del sufragio universal porqué privaría del derecho de voto una entera categoría de ciudadanos ${ }^{335}$. Esta afirmación no es exacta, porqué la exclusión no afecta a una «categoría» de personas seleccionadas por características intrínsecas que la distinguan de otras, sino a personas que han sido individualmente condenadas, con un justo proceso legal, para haber individualmente violado normas penales sancionadas con la pena de la detención: entonces por comportamientos que adoptaron libremente (es decir como personas dotadas de libre albedrío) aun si en presencia de una prohibición dispuesta por la ley penal ${ }^{336}$. La afirmación aquí criticada tiene el mismo valor de una afirmación cuyo contenido sea que con la prisión se priva de la libertad personal una entera categoría de personas. En ambos casos, la categoría es constituida no con finalidades discriminatorias, sino como consecuencia de la violación de preceptos penales y con la finalidad última de asegurar el respeto de la ley y de garantizar la paz social. La categoría de la que se habla no existe en sí, sino solo como suma de las personas que se encuentran en dicha situación, como consecuencia de sus actos voluntarios, que consisten en la violación de normas penales, constatada por jueces independientes y imparciales en cada caso concreto.

Si estos argumentos prospectan una justificación posible y plausible del disenfranchisement, su finalidad es llegar a la conclusión que ella pueden justificar la limitación del derecho de voto en los estados miembros del Consejo de Europa en el ejercicio de su margen de apreciación nacional y no la de afirmar que esta conclusión sea la única compatible con la naturaleza del derecho de voto y de la istitución social denominada cárcel. Considerado el texto del art. 3 del Prot. Ad. n. 1 y las tradiciones constitucionales nacionales, el derecho a elecciones libres previsto por el CEDH puede ser interpretado sea en la perspectiva esbozada en este ensayo, sea como derecho subjetivo perfecto: y no es competencia del Tribunal de Estrasburgo, sino de los estrado miembro cerrar esta alternativa, que el Tribunal tendría que dejar abierta, limitandose a controlar los confines exteriores de las diferentes concepciones del derecho de voto compatibles con el citado art. $3^{337}$. Es verdad, de

\footnotetext{
${ }^{335}$ Se vea Frodl contra Austria, nr. 24; Scoppola contra Italia (n. 3) - GC, nr. 96; Anchugov and Gladkov v. Russia, nr. 96; Söyler contra Turquía, nr. 34.

${ }^{336}$ Este argumento fue utilizado por un tribunal federal de Estados Unidos en el caso Wesley v. Collins, 605 F. Supp. 802, 813 (citado por A.C. Ewald, “Civic death”, cit., p. 1078-79), según el cual los condenados are not disenfranchised based on any immutable characteristic, such as race, but on their conscious decision to commit an act for which they assume the risk of detention and punishment.

337 Se retoma aquí un argumento ya expuesto en la dissenting opinion en el fallo Sauvé v. Canada: «s. 1 of the Charter requires that this Court look to the fact that there may be different social or political philosophies upon which justifications for or against the limitations of
} 
hecho, que - como afirmó el Tribunal Supremo de Canadá en el caso Sauvé - it is for the Courts, unaffected by the shifting winds of public opinion and electoral interests, to safeguard the right to vote ${ }^{338}$. Sin embargo, lo que es el derecho de voto I cuales son sus límites tiene que ser definido sobre la base de un material normativo mas amplio y rico, en el cual es necesario incluir, en el caso del CEDH, las tradiciones constitucionales nacionales y su diversidad, al fin de evitar que la indeterminación de las disposiciones sobre los derechos permita a los jueces de imponer su concepció de filosofía social y política.

De toda manera, también en una perspectiva, como la adoptada aquí, favorable a la posibilidad que los estados supriman el derecho de voto de los prisoneros condenado a la reclusión por el período de expiación de la condena, sobra un espacio para unos límites y para un control sobre la proporcionalidad de la restricción. De hecho, la afirmación que se encuentra en unas de las sentencias analizadas en los párrafos anteriores, según la cual la privación del derecho de voto no puede ser impuesta a la ligera ${ }^{339}$, parece en principio aceptable. Pero, a nuestro parecer, la consecuencia de una condena a una pena de prisión, es decir la privación de la libertad personal, afecta a la libertad y a la autonomía de la persona en manera mucho más intensa que la privación del derecho de voto. Entonces, si hay una consecuencia sobre la cual un sistema jurídico tiene que ser muy prudente, es la privación de la libertad personal que tendría que ser siempre una medida of last resort - y no la consecuencia ulterior del disenfranchisement. Una vez que se llegue a la conclusión que la primera sanción es inevitable, parece razonable excluir el condenado también del derecho de elegir a los representantes de la nación. Por lo tanto, parece condivisible la tesis según la cual [The] deprivation of political rights is proportionate because it lasts no longer than her imprisonment ${ }^{340}$.

Este paralelismo entre la privación de la libertad personal y la limitación

rights may be based. In such a context, where this Court is presented with competing social or political philosophies relating to the right to vote, it is not by merely approving or preferring one that the other is necessarily disproved or shown not to survive Charter scrutiny. If the social or political philosophy advanced by Parliament reasonably justifies a limitation of the right in the context of a free and democratic society, then it ought to be upheld as constitutional. In the realm of competing social or political philosophies, reasonableness is the predominant s. 1 justification consideration. Section 1 of the Charter does not constrain Parliament or authorize this Court to prioritize one reasonable social or political philosophy over reasonable others, but only empowers this Court to strike down those limitations which are not reasonable and which cannot be justified in a free and democratic society. The decision before this Court is therefore not whether or not Parliament has made a proper policy decision, but whether the policy position chosen by Parliament is an acceptable choice amongst those permitted under the Chartern.

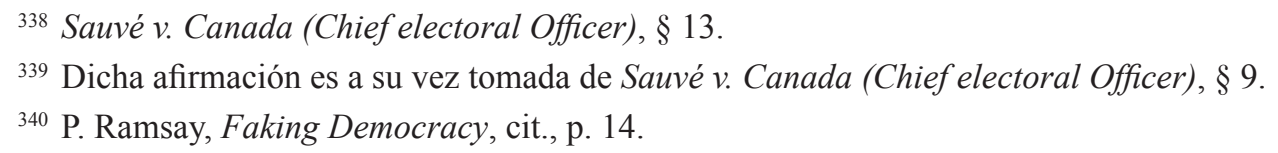


del derecho de voto podría encontrar dos excepciones: de un lado la privación del derecho de voto no tendría que aplicarse, en virtud de la presunción de inocencia ${ }^{341}$, a los prisoneros todavia no condenados o cuya condena no sea definitiva (y esto porqué en casos de este tipo la privación de la libertad personal corresponde a finalidades cautelares, pero la persona es presumida inocente y por esta razón la suspensión de sus derechos políticos podría ser desproporcionada); en segundo lugar, la conexión entre prisión y privación del derecho de voto tendría que funcionar no solo para justificar la privación del derecho, sino también para excluir, en principio, el life disenfranchisement, también en los crímenes más graves: no se quiere decir, aquí, que el life disenfranchisement sea en absoluto contrario al principio de proporcionalidad, sino solo que tendría que aplicarse solo a crímenes de gravedad excepcional (en principio los mismos para los cuales se admite - o se admitía - la pena de la reclusión por la vida, aun si de hecho se procede a la liberación anticipada del condenado).

Parece razonable llegar a esta conclusión no solo por razones de protección de intereses individuales, sino también para evitar que el número de las personas privadas del derecho de voto llegue a cantidades elevadas, como pasa en unos estados del sur de Estados Unidos ${ }^{342}$, en los cuales el porcentaje de electores privados del derecho de voto llega en unos casos al 13 por ciento del electorado, alterando, entre otras cosas, la fuerza electoral de los diferentes grupos raciales.

341 ...reconocida por muchas constituciones y también por el CEDH (art. 6.2).

342 A.C. Ewald, “Civic death”, cit., p. 1045-1046. En este mismo ensayo se subraya que el fenómeno tiene una «dimensión racial» (p. 1048 y literatura allí citada). 